Research Article

\title{
Consolidation Behavior and Compression Prediction Model of Coastal Cement Soil Modified by Nanoclay
}

\author{
Wenjie Yu $\mathbb{D}^{1},{ }^{1}$ Na Li $\left(\mathbb{D},{ }^{1}\right.$ Mengdan Dai $\mathbb{D}^{1},{ }^{1}$ Dongliang An $\left(\mathbb{D},{ }^{1}\right.$ Biao Qian, ${ }^{2}$ Wei Wang, \\ and Ping Jiang $\mathbb{D}^{1}$ \\ ${ }^{1}$ School of Civil Engineering, Shaoxing University, Shaoxing 312000, China \\ ${ }^{2}$ Tongchuang Engineering Design Co. Ltd., Shaoxing 312000, China
}

Correspondence should be addressed to Na Li; lina@usx.edu.cn and Ping Jiang; jiangping@usx.edu.cn

Received 19 February 2021; Revised 13 April 2021; Accepted 16 May 2021; Published 26 May 2021

Academic Editor: Yubo Jiao

Copyright (c) 2021 Wenjie Yu et al. This is an open access article distributed under the Creative Commons Attribution License, which permits unrestricted use, distribution, and reproduction in any medium, provided the original work is properly cited.

Coastal cement soil modified by nanoclay (NCS) has particular research significance as a modification approach to improve the high compressibility of coastal cement soil (CCS). At curing ages of 7 days and 28 days, consolidation and SEM tests were performed on 6 groups of NCS samples with a nanoclay content between $0 \%$ and $10 \%$ and 6 groups of CCS samples with a cement content between 10 and $20 \%$, and a compression prediction model was established based on the test results. Test results show that (1) there is a linear interval for the improvement effect of the increment of cement content on the compression of CCS samples. In this test, the cement content in this interval is between $12 \%$ and $18 \%$. CCS with a cement content of $18 \%$ is preferred. (2) The improvement effect on the compression of the sample is better with a nanoclay content of $4 \%$ and $8 \%$, but poor with a content of $2 \%$. At a consolidation pressure between $100 \mathrm{kPa}$ and $800 \mathrm{kPa}$, NCS with a nanoclay content of $4 \%$ is preferred. (3) Adhesion is better with a nanoclay content of $4 \%$, and the filling effect is better with a content of $8 \%$. (4) The cosine-power functionexponential model is established, and the measured data are fitted, and a prediction model for the compression amount of CCS and NCS is established.

\section{Introduction}

With the continuous development of economic construction, determining how to carry out engineering construction in coastal soft soil areas has become a problem that many countries need to solve during the development process. For example, due to the current situation of large amounts of coastal areas, China, South Korea, Singapore, and other countries have to carry out engineering construction in these areas to meet their own development needs [1-4]. Coastal soft soil has the characteristics of high natural water content, large compressibility, and low strength [5], which makes it difficult to meet design requirements and requires cement reinforcement $[6,7]$. Many studies have shown that cement is an important material to improve the compressibility of soft soil. Generally, improvement increases at the beginning and then decreases with the increase of cement content $[8,9]$. Filling and chemical reactions are the main reason for the modification effect of nanomaterials on cement soil [10]. Kwon et al. [11] carried out unconfined compressive strength (UCS) tests on cement soil with different clay content and particle fineness. The research results showed that the particle fineness could affect the compressibility of the sample. The sample strength was high, and the water absorption was low, with a clay content of $14.3 \%$. Existing research results show that high compressibility is the main factor restricting the use of coastal cement soil (CCS) as foundation soil $[12,13]$, although cement has a better effect on improving the compressibility of soft soil $[14,15]$.

With the development of nanotechnology [16], nanomaterials with their unique advantages are gradually favored by civil engineers. Although cement can fill most of the pores in the soil, there are still some nanopores that need to be filled with nanomaterials. Therefore, many studies have been focused on nano-modified cement soil (NCS). Nano-SiO can improve the durability of CCS [17]. Nano-MgO can 
improve shear resistance [18], compression [19, 20], and erosion resistance [21] of cement soil. Nanoclay can improve the frost resistance [22], compressive strength, and flexural strength $[23,24]$ of concrete. Choobbasti and Kutanaei [25] improved the flexural strength of cement soil by adding nano- $\mathrm{SiO}_{2}$, with the characteristics of higher activity and water absorption. UCS tests were performed on cement soils with different nano- $\mathrm{SiO}_{2}$ content. The research results showed that the improvement of compressive strength was better with $4 \%$ content [25]. Zhang et al. [26] analyzed the macroscopic mechanics and microstructure of cement soil mixed with nanoclay utilizing X-ray diffraction (XRD) and mercury injection tests. The results showed that the flexural strength of the sample increased by $25.94 \%$ with a nanoclay content of 3\%. Nanoclay was uniformly distributed and filled the pores inside the cement soil and combined with hydrated calcium silicate to wrap ettringite and other crystals together to improve the strength. The above results prove that cement content is the main factor affecting the compressibility of cement soil. In addition to filling pores, nanomaterials can also be combined with cement hydration reaction products.

At present, there are fewer studies on the consolidation characteristics of CCS and NCS, and further exploration is needed to provide data support for solving the high compressibility of CCS. In this study, consolidation tests on CCS and NCS samples were conducted. The improvement effect of cement content on the consolidation characteristics of CCS was studied, and a compression prediction model was established based on the test results, providing data references for the application of CCS. The improvement effect of nanoclay content on the consolidation characteristics of CSS was also investigated, and a compression prediction model was established for NCS with better modification effect, which was convenient for the promotion of NCS, and is expected to provide a reference for solving the high compressibility of CCS.

\section{Test Overview}

2.1. Test Materials and Equipment. The coastal soft soil used throughout this experimental test was collected from a site in Shangyu Industrial Zone, Binhai New Town, Shaoxing City, Zhejiang Province, China. The specific physical properties are summarized in Table 1. The cement used was PO 32.5 composite Portland cement, and its specific physical and mechanical properties are shown in Table 2. The nanoclay selected has high-purity and ultrafine particle size, and the properties of it are shown in Table 3. The water used was ordinary tap water. This test equipment was a fully automated oedometer (air pressure) (model TKA-STC-1F).

2.2. Experimental Scheme. The rapid consolidation test method was adopted in this test, and the loading was from $12.5 \mathrm{kPa}$ to $1600 \mathrm{kPa}$ with the order of the loading ratio of 2 , for a total of 8 pressure levels. Consolidation tests of CCS and NCS samples were conducted with 22 groups of 5 samples in each group, for a total of 110 samples.
2.2.1. Design Scheme of CCS Samples. The samples were coded as CCS-X-Y, where CCS represents coastal cement soil, $X$ represents its curing age, and $Y$ represents its cement content. The specific sample design scheme is shown in Table 4.

2.2.2. Design Scheme of NCS Samples. The samples were coded as NCS-X-Y(-Z), where NCS represents nano-modified cement soil, $X$ represents its curing age, $Y$ represents its cement content, and $Z$ represents its nanoclay content. The specific sample design scheme is shown in Table 5 .

Each set of tests was repeated 5 times, and the obtained results were processed. The investigated compression value of CCS-7-10 was taken as an example, and the results are summarized in Figure 1.

In order to better reflect the test results, two investigated data with the largest and smallest compression amounts were first removed, and then, the relative standard deviation (RSD) of the remaining three investigated data was calculated. If the RSD was less than $5 \%$, the average value of the remaining three sets of data was directly used as the standard to analyze the test results. If the RSD was greater than or equal to $5 \%$, a new set of five samples' test should be carried again until the RSD was less than $5 \%$.

After excluding the two sets of data with the largest and smallest compression amounts, the RSD of the CCS-7-10 group was $1.5 \%$ less than $5 \%$, with an average value of 6.995 , which was used as the standard value to analyze the test results. The test results of other groups were also processed according to this method.

2.3. Sample Preparation. The samples of CCS and NCS were prepared according to the test scheme and geotechnical test standards [27]. The preparation steps are stated as below:

(1) The coastal soft soil was crushed and soaked in water.

(2) The soaked coastal soft soil is filtered by a fine sieve with $2 \mathrm{~mm}$ opening, and then, its moisture content is measured.

(3) The bolt-type flow-plastic soil ring vibrator was put on the experimental platform.

(4) The weighed quantities of coastal soft soil, cement, nanoclay, and water were mixed and stirred. Then, the combination of CCS and NCS, which was evenly mixed, was poured into the bolt-type flow-plastic soil ring vibrator with a size of $61.8 \mathrm{~mm} \times 20 \mathrm{~mm}$ for selfcompacting.

After completion of the self-compacting, the sample was taken out from the vibrator and put into a constant temperature curing box for curing.

2.4. Test Procedure. The samples of CCS and NCS were carried out the rapid consolidation test according to the test scheme and geotechnical test standards [27]. The procedure is as below: 
TABLE 1: Coastal soft soil physical properties.

\begin{tabular}{lccccc}
\hline Density $\rho\left(\mathrm{kN} / \mathrm{m}^{3}\right)$ & Water content $(\%)$ & Plastic limit $(\%)$ & Liquid limit $(\%)$ & Plasticity index & Liquidity index \\
\hline 18.2 & 31.7 & 24.6 & 40.9 & 16.3 & 0.44 \\
\hline
\end{tabular}

Table 2: Physical and mechanical properties of PO 32.5 composite Portland cement.

\begin{tabular}{lcccccc}
\hline $\begin{array}{l}\text { Fineness } \\
(\%)\end{array}$ & $\begin{array}{c}\text { Initial setting } \\
\text { time }(\mathrm{min})\end{array}$ & $\begin{array}{c}\text { Final setting } \\
\text { time }(\mathrm{min})\end{array}$ & $\begin{array}{c}3 \mathrm{~d} \text { compressive } \\
\text { strength }(\mathrm{MPa})\end{array}$ & $\begin{array}{c}28 \mathrm{~d} \text { compressive } \\
\text { strength }(\mathrm{MPa})\end{array}$ & $\begin{array}{c}3 \mathrm{~d} \text { flexural } \\
\text { strength }(\mathrm{MPa})\end{array}$ & $\begin{array}{c}28 \mathrm{~d} \text { flexural } \\
\text { strength }(\mathrm{MPa})\end{array}$ \\
\hline 3.4 & 210 & 295 & 26.9 & 48.1 & 4.9 & 9.0 \\
\hline
\end{tabular}

TABLE 3: Some properties of nanoclay.

\begin{tabular}{lccc}
\hline The average particle size (um) & Purity (\%) & $\mathrm{pH}$ value & Main element \\
\hline $1-3$ & 98 & 7.6 & $\mathrm{Si}, \mathrm{O}, \mathrm{Al}$, and $\mathrm{Fe}$ \\
\hline
\end{tabular}

TABLE 4: Sample design scheme of coastal cement soil (CCS).

\begin{tabular}{|c|c|c|c|c|}
\hline Sample code & Cement content (\%) & Water content $(\%)$ & Number of samples in $7 \mathrm{~d}$ & Number of samples in $28 \mathrm{~d}$ \\
\hline CCS-7-10 & 10 & \multirow{12}{*}{80} & 5 & \\
\hline CCS-7-12 & 12 & & 5 & \\
\hline CCS-7-14 & 14 & & 5 & \\
\hline CCS-7-16 & 16 & & 5 & \\
\hline CCS-7-18 & 18 & & 5 & \\
\hline CCS-7-20 & 20 & & 5 & \\
\hline CCS-28-10 & 10 & & & 5 \\
\hline CCS-28-12 & 12 & & & 5 \\
\hline CCS-28-14 & 14 & & & 5 \\
\hline CCS-28-16 & 16 & & & 5 \\
\hline CCS-28-18 & 18 & & & 5 \\
\hline CCS-28-20 & 20 & & & 5 \\
\hline
\end{tabular}

TABLE 5: Sample design scheme of coastal cement soil modified by nanoclay.

\begin{tabular}{|c|c|c|c|c|c|}
\hline Sample code & Cement content (\%) & Nanoclay content (\%) & Water content $(\%)$ & Number of samples in $7 \mathrm{~d}$ & Number of samples in $28 \mathrm{~d}$ \\
\hline NCS-7-10 & & 0 & & 5 & \\
\hline NCS-7-10-2 & & 2 & & 5 & \\
\hline NCS-7-10-4 & & 4 & & 5 & \\
\hline NCS-7-10-6 & & 6 & & 5 & \\
\hline NCS-7-10-8 & & 8 & & 5 & \\
\hline NCS-7-10-10 & & 10 & & 5 & \\
\hline NCS-28-10 & 10 & 0 & 80 & & 5 \\
\hline NCS-28-10-2 & & 2 & & & 5 \\
\hline NCS-28-10-4 & & 4 & & & 5 \\
\hline NCS-28-10-6 & & 6 & & & 5 \\
\hline NCS-28-10-8 & & 8 & & & 5 \\
\hline $\begin{array}{l}\text { NCS-28-10- } \\
10\end{array}$ & & 10 & & & 5 \\
\hline
\end{tabular}

(1) Saturated sample: put the prepared sample into a saturated container for saturation.

(2) Install the sample: put the guard ring, large filter stone, limit ring, filter paper, saturated sample, filter paper, small filter stone, positioning ring, and pressurized cover into the consolidation container in order from bottom to top and add water until it is submerged in the sample.

(3) Install the consolidation vessel: put the assembled consolidation container into the pressurizing device 


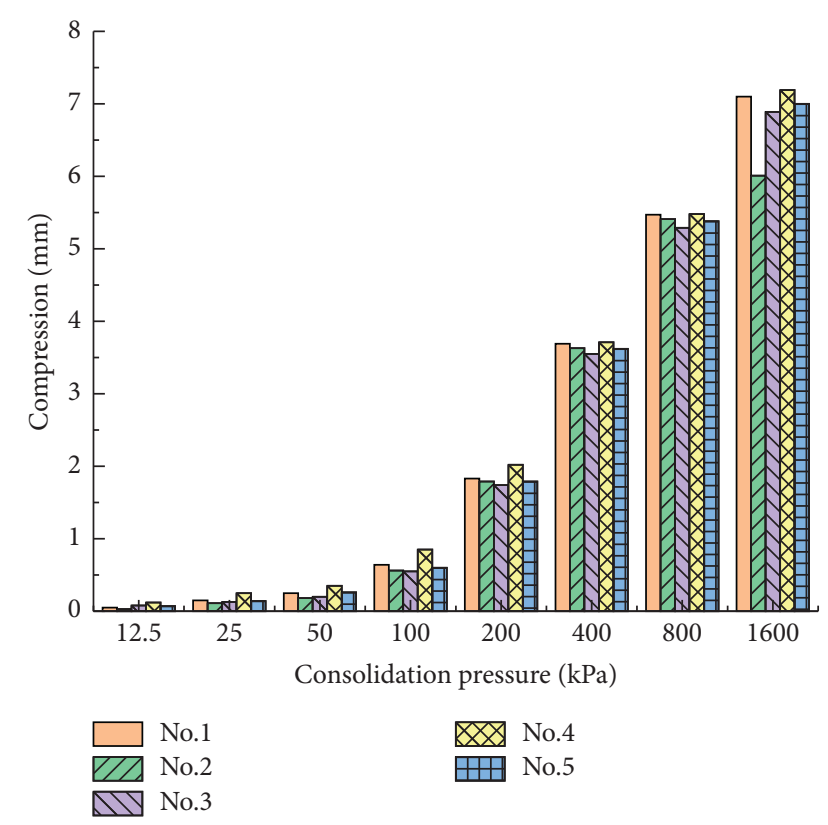

FIGURE 1: Investigated compression value of five samples of CCS-7-10.

and adjust the fixing bolt to make the bottom of the pressurized cover tightly contact.

(4) Adjust the displacement sensor: touch the displacement pointer of the displacement sensor with the top of the fixing bolt and fix the displacement sensor when the number in the displacement sensor displays a number in the range of 6 to 8 .

(5) Select the pressure level: the pressure range is controlled within $12.5 \mathrm{kPa} \sim 1600 \mathrm{kPa}$.

(6) Pressure test: select the test specification, consolidation type, and deformation per hour in sequence on the software. Then, turn on the gas compressor and start the consolidation test.

(7) Organize the instrument: when all pressure levels are completed, stop the test. Quickly remove the consolidated container from the pressurizing device and take out the consolidated sample. Organize the instrument and turn off the software and power.

\section{Test Results and Analysis of CCS}

3.1. Compression-Pressure Analysis. The compression amount is the difference between the height of the sample stabilized at a certain consolidation pressure and the initial sample, which is calculated as shown in the following formula:

$$
d_{i}=\sum \Delta h_{i}
$$

where $d_{i}$ represents the compression amount $(\mathrm{mm})$ at a certain consolidation pressure and $h_{i}$ represents the total deformation $(\mathrm{mm})$ of the sample after consolidation and stabilization at the same consolidation pressure.

According to the test results and formula (1), the compression amount of CCS samples at different consolidation pressures was obtained, and the compression amount-consolidation pressure curves ( $d$ - $p$ curves) of CCS7 and CCS-28 were drawn, as shown in Figures 2 and 3.

Figure 2 indicates that the $d$ - $p$ curves of the CCS-7 samples are all increasing concave-convex curves. When the consolidation pressure is between $0 \mathrm{kPa}$ and $400 \mathrm{kPa}$, the compression of the sample increases slow at the beginning and then fast; however, between $400 \mathrm{kPa}$ and $1600 \mathrm{kPa}$, it was first fast and then slow. The compression of the sample decreases continuously with the increase of cement content at the same consolidation pressure. When the consolidation pressure is greater than or equal to $200 \mathrm{kPa}$ and cement content is between $12 \%$ and $16 \%$, each $2 \%$ increment of cement content has a better improvement effect on the compression of the sample that is reduced by about $0.3 \mathrm{~mm}$. When the cement content is $10 \%$ and $18 \%, 2 \%$ increment of cement content has a moderate improvement effect on the compression that is reduced by $0.1 \mathrm{~mm}$.

Figure 3 indicates that the $d$ - $p$ curves of CCS-28 are similar to those of CCS-7. As the cement content increases, the compression of the sample decreases continuously at the same consolidation pressure. When the consolidation pressure is greater than or equal to $200 \mathrm{kPa}$ and cement content is $10 \%, 14 \%$, and $16 \%, 2 \%$ increment of cement content has a better effect on the compression amount of the sample, reducing the compression amount by about $0.4 \mathrm{~mm}$. When the cement content is $12 \%$ and $18 \%, 2 \%$ increment of cement content has a moderate effect on the compression amount of the sample, reducing the compression amount by about $0.2 \mathrm{~mm}$.

The compression data of CCS samples at different curing ages were compared, as shown in Table 6. This table indicates that when the cement content is between $10 \%$ and $14 \%$ and the consolidation pressure is less than or equal to $400 \mathrm{kPa}$, the differences between the compression amounts of CCS samples at different curing ages gradually increase with consolidation pressure, but decrease with increased cement content. When the pressure is greater than $400 \mathrm{kPa}$, the differences between the compression amount at different curing ages gradually decrease with pressure increases but increase with cement content. When the cement content is greater than $14 \%$, the difference between the compression amounts of CCS samples at different curing ages gradually increases with increase cement content. The results indicate that the higher the cement content, the better the improvement effect of curing age on the compression of the sample.

The above results show a mutual improvement effect of cement content and curing age on the compression amount of CCS. At a curing age of 7 days with a cement content between $10 \%$ and $16 \%$ and at a curing age of 28 days with a cement content of $10 \%, 14 \%$, and $16 \%$, a $2 \%$ increment of cement content had a better improvement effect on the compression of the sample. This is because when the cement content exceeds a certain level (12\% in this test), a more complete cement-soil skeleton can be formed. When the cement content is too large (18\% in this test), the increasing content will make the cement particles wrap each other and slow down the increase rate of hydration reactions. 


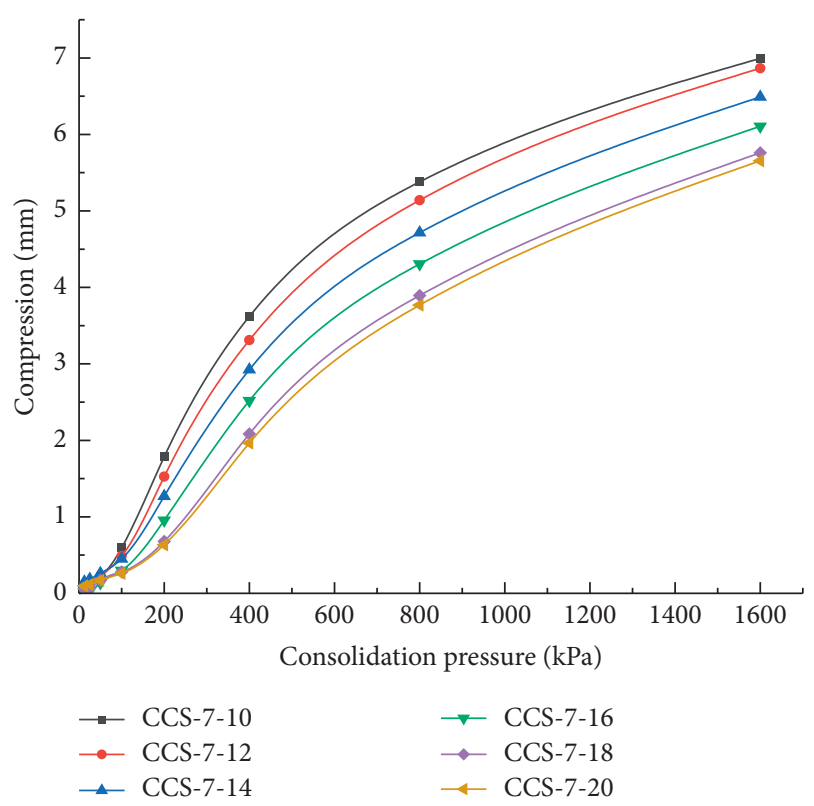

FIGURE 2: The compression amount-consolidation pressure curves of CCS-7.

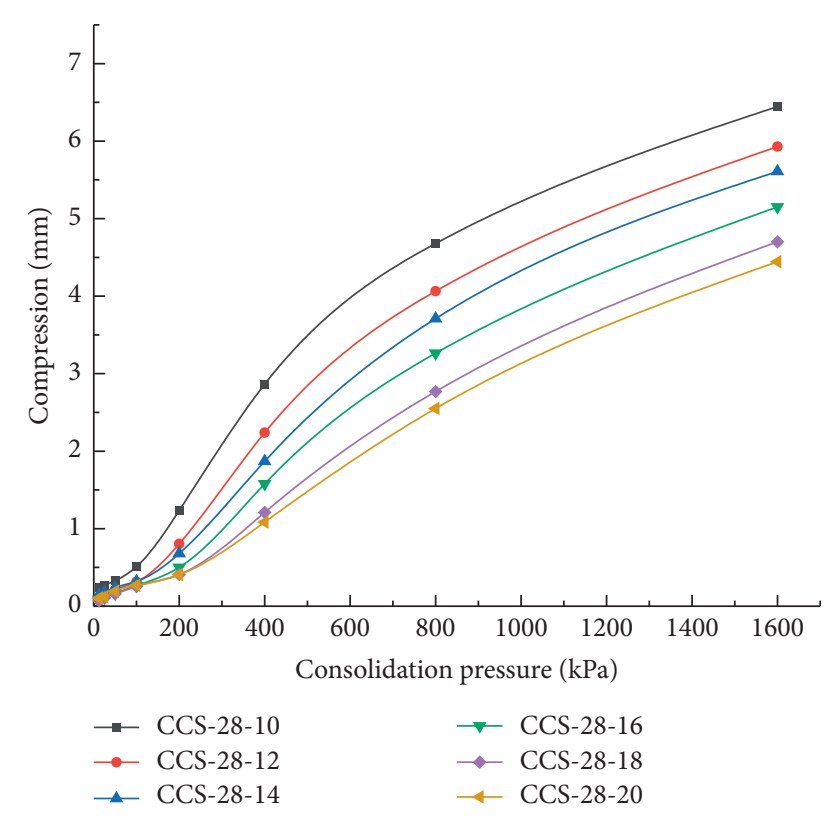

FIGURE 3: The compression amount-consolidation pressure curves of CCS-28.

Therefore, on the premise of meeting engineering requirements, CCS with a cement content between $12 \%$ and $18 \%$ is preferred.

3.2. Analysis of Void Ratio Changes. The void ratio is the ratio of pore volume to solid volume of the sample, calculated as shown in the following formula:

$$
e_{0}=\frac{\left(1+w_{0}\right) G_{s} p_{w}}{p_{0}}-1
$$

where $e_{0}$ represents the initial void ratio, $w_{0}$ represents water content, $G_{s}$ represents particle specific gravity, $p_{w}$ represents the density of water at $20^{\circ} \mathrm{C}$, and $p_{0}$ represents the density of the sample.

The void ratio $e_{i}$ of the sample at a fixed consolidation pressure can be calculated according to the following formula:

$$
e_{i}=e_{0}-\frac{1+e_{0}}{h_{0}}-\Delta d_{i}
$$

where $h_{0}$ represents the initial height of the sample $(20 \mathrm{~mm})$ and $\Delta d_{i}$ represents the compression amount of the sample after stabilization at a certain consolidation pressure.

Based on the test results and equations (1)-(3), the void ratios of CCS-7 and CCS-28 and their changes were obtained, as shown in Figure 4, where Ivr represents the initial void ratio and Fvr represents the final void ratio.

It can be seen in Figure 4 that the initial void ratio of the sample increases with cement content. For every $2 \%$ increase in cement content, the largest increase in initial porosity is in CCS-7-14 and CCS-28-20, with a value of 0.04. In other cases, it remains between 0.02 and 0.03 . With the same cement content, the initial and final void ratio of the sample increased with the curing age. The initial void ratio increased the most (4.8\%) with a cement content of $10 \%$, and the final void ratio is highest increased the most (20.5\%) with a cement content of $20 \%$. The change in the void ratio of the sample decreased with curing age, and this reduction effect increased with cement content. The maximum value is 0.17 , with a cement content of $20 \%$. The above research results show that the addition of cement will improve the initial void ratio of the sample, and the improvement effect of the cement increment on the void ratio is approximately the same. The effect of cement on the initial pore ratio can be strengthened by increasing the curing age.

3.3. Compression Modulus-Pressure Analysis. The compression modulus is an important index for evaluating the compressibility of soil, which can be calculated according to the following formula:

$$
E_{s}=\frac{1+e_{0}}{a_{v}}
$$

where $a_{v}$ represents the coefficient of compressibility. In engineering, the compressibility of soil is often distinguished by a coefficient of compressibility between $100 \mathrm{kPa}$ and $200 \mathrm{kPa}$ and is calculated by the following formula:

$$
\begin{aligned}
a_{v} & =\frac{e_{i}-e_{i+1}}{p_{i+1}-p_{i}}, \\
a_{1-2} & =\frac{e_{100}-e_{200}}{p_{200}-p_{100}},
\end{aligned}
$$

where $p_{i}$ represents a certain consolidation pressure. $a_{1-2}$ of CCS-7 and CCS- 28 are obtained according to formula (5), shown in Figures 5 and 6. When $\mathrm{a}_{1-2}$ is less than $0.1 \mathrm{MPa}$, it refers to low-compressibility soil. When $a_{1-2}$ is between $0.1 \mathrm{MPa}$ and $0.5 \mathrm{MPa}$, it refers to medium-compressibility 
TABLE 6: Compression of CCS at different consolidation pressures.

\begin{tabular}{|c|c|c|c|c|c|c|}
\hline \multirow{2}{*}{ Cement content $(\%)$} & \multirow{2}{*}{ Curing age (d) } & \multicolumn{5}{|c|}{ The amount of compression under consolidation pressure $(\mathrm{mm})$} \\
\hline & & $100 \mathrm{kPa}$ & $200 \mathrm{kPa}$ & $400 \mathrm{kPa}$ & $800 \mathrm{kPa}$ & $1600 \mathrm{kPa}$ \\
\hline \multirow{2}{*}{10} & 7 & 0.595 & 1.785 & 3.620 & 5.380 & 6.995 \\
\hline & 28 & 0.510 & 1.235 & 2.865 & 4.680 & 6.445 \\
\hline \multirow{2}{*}{12} & 7 & 0.485 & 1.525 & 3.310 & 5.140 & 6.865 \\
\hline & 28 & 0.315 & 0.805 & 2.240 & 4.065 & 5.930 \\
\hline \multirow{2}{*}{14} & 7 & 0.450 & 1.270 & 2.925 & 4.715 & 6.490 \\
\hline & 28 & 0.320 & 0.680 & 1.870 & 3.710 & 5.610 \\
\hline \multirow{2}{*}{16} & 7 & 0.300 & 0.955 & 2.520 & 4.305 & 6.105 \\
\hline & 28 & 0.265 & 0.500 & 1.580 & 3.265 & 5.150 \\
\hline \multirow{2}{*}{18} & 7 & 0.280 & 0.680 & 2.085 & 3.895 & 5.760 \\
\hline & 28 & 0.255 & 0.410 & 1.210 & 2.770 & 4.700 \\
\hline \multirow{2}{*}{20} & 7 & 0.260 & 0.635 & 1.965 & 3.770 & 5.655 \\
\hline & 28 & 0.270 & 0.405 & 1.085 & 2.550 & 4.445 \\
\hline
\end{tabular}
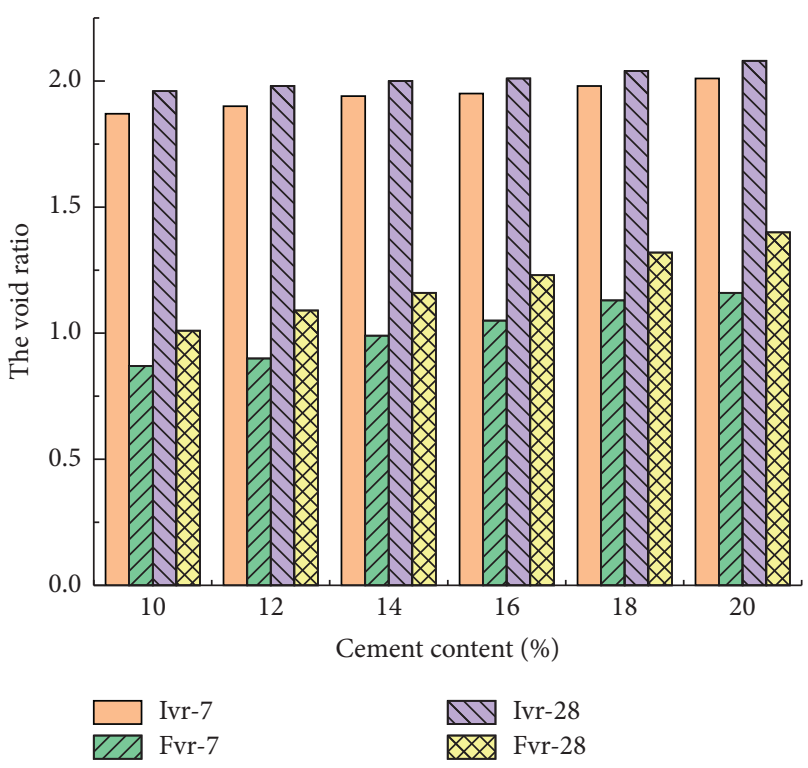

FIgURE 4: Change in the void ratio of CCS.

soil. When $\mathrm{a}_{1-2}$ is greater than $0.5 \mathrm{MPa}$, it refers to highcompressibility soil.

As shown in Figure 5, when the cement content is between $10 \%$ and $18 \%$, the sample decreases approximately linearly with the increased cement content, indicating that cement content in this interval has a better improvement effect on the compressibility of the sample. When the cement content is between $18 \%$ and $20 \%$, the change of $a_{1-2}$ is small at only $0.045 \mathrm{MPa}^{-1}$, indicating that increasing the cement content at this time has an balanced improvement effect. The $a_{1-2}$ of CCS-7 is more than $0.5 \mathrm{MPa}$, which means it refers to high-compressibility soil.

As shown in Figure 6, when the cement content is between $10 \%$ and $12 \%, a_{1-2}$ changes the most, and the coefficient of compressibility of the sample decreases by $0.343 \mathrm{MPa}^{-1}$, which indicates that increasing the cement content at this time has the best improvement effect. When the cement content is between $18 \%$ and $20 \%, a_{1-2}$ changes slightly, only $0.028 \mathrm{MPa}^{-1}$, indicating that increasing the

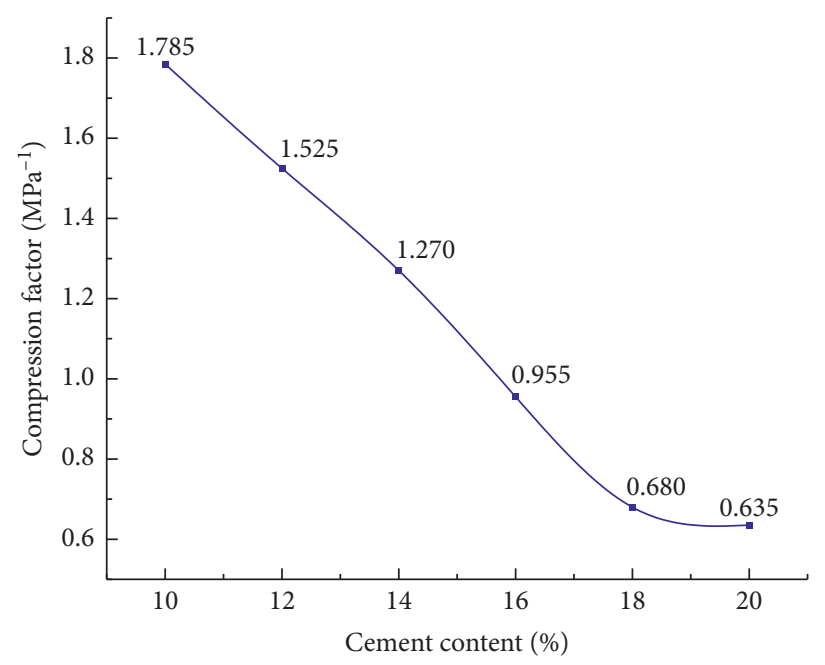

FIgURE 5: $a_{1-2}$ of CCS -7 with different cement content.

cement content at this time has an average improvement effect. Numerically, the value of $a_{1-2}$ of CCS at a curing age of 28 days decreases from $1.074 \mathrm{MPa}^{-1}$ to $0.208 \mathrm{MPa}^{-1}$, and the sample changes from high- to medium-compressibility soil. These results show that the improvement effect of cement increment on the compressibility of the sample is better with a cement content between $12 \%$ and $18 \%$.

Es values of CCS-7 and CCS-28 are obtained from formula (4), and the Es-p curve is drawn, as shown in Figures 7 and 8. Regarding the applied consolidation pressure, $12.5 \mathrm{kPa}$ and $25 \mathrm{kPa}$, which represent prestressing, are not considered. The compression modulus is an important parameter to characterize compressibility in a fixed pressure range. Therefore, the compression modulus is studied with a consolidation pressure between $100 \mathrm{kPa}$ and $1600 \mathrm{kPa}$ in this test. The structure between the particles of cement hydration reaction products will be destroyed when the consolidation pressure is near $800 \mathrm{kPa}$.

It can be seen from Figure 7 that the change of $E s$ of a single sample shows a concave trend. When the cement content is $10 \%$ and $12 \%$, the minimum value of $E s$ of the sample appears at a consolidation pressure of $200 \mathrm{kPa}$; when 


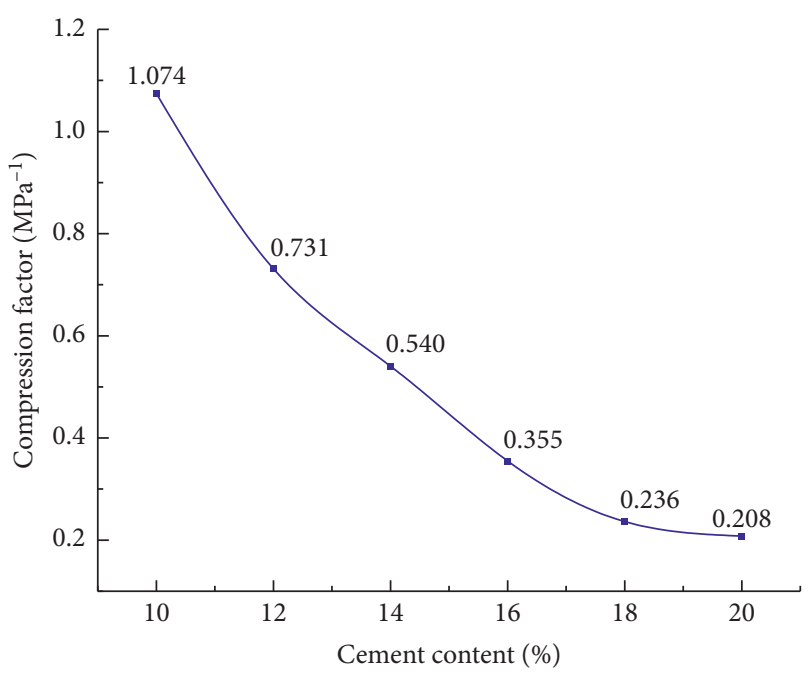

FIGURE 6: $a_{1-2}$ of CCS-28 with different cement content.

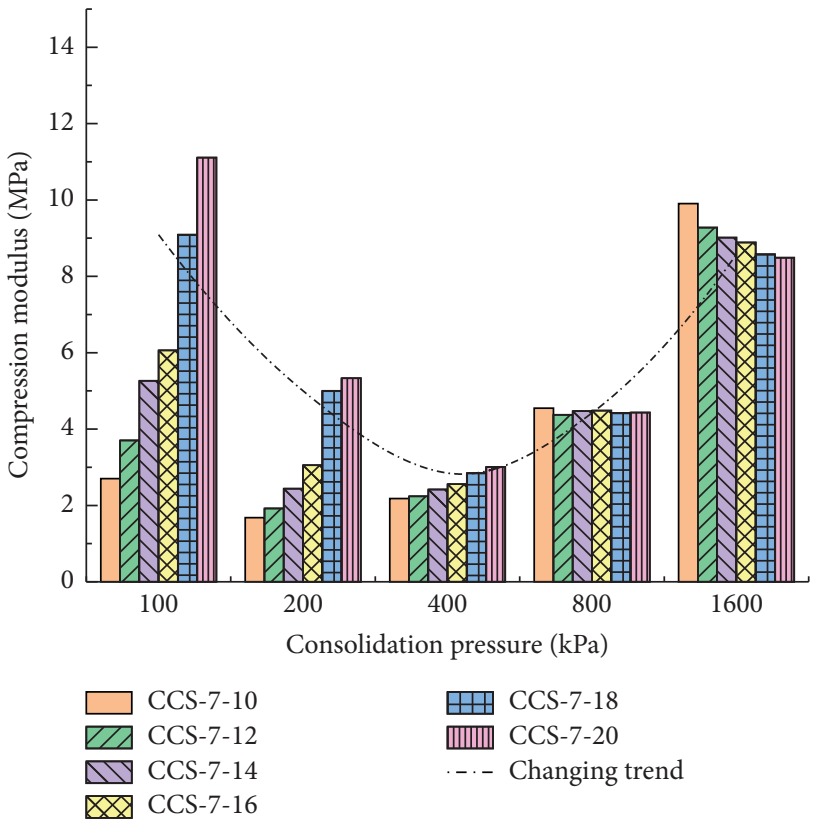

FIgURE 7: Es of CCS-7 with different cement content.

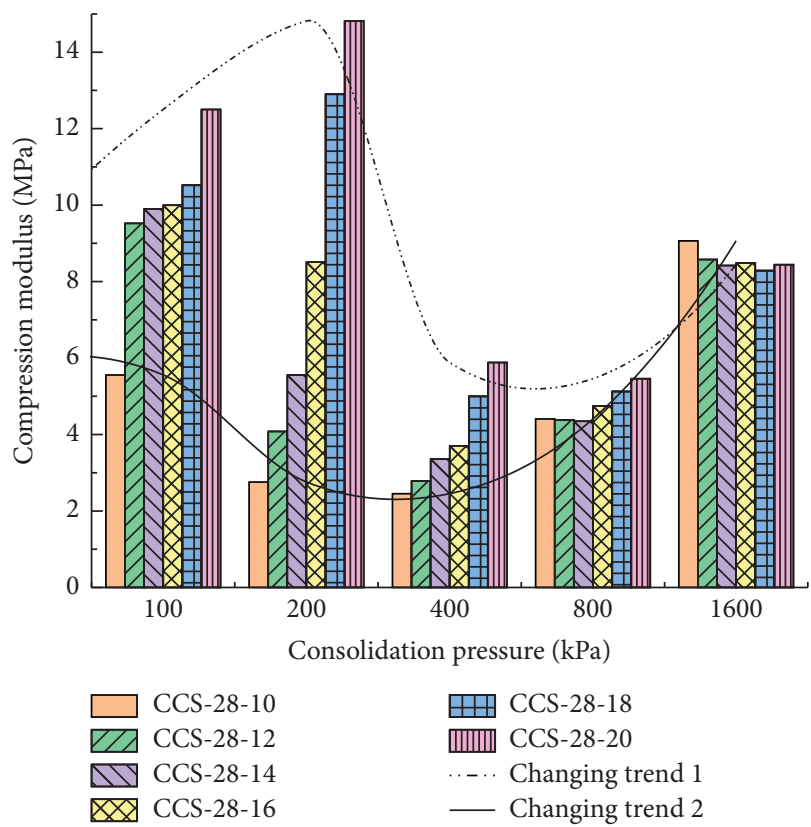

FIGURE 8: Es of CCS-28 with different cement content. the content is greater than $12 \%$, it appears at a pressure of $400 \mathrm{kPa}$. When the consolidation pressure is between $100 \mathrm{kPa}$ and $800 \mathrm{kPa}$, the increasing cement content can increase $E s$ of the sample. Overall, the improvement effect on Es of the sample is the best with a cement content of $18 \%$. When the consolidation pressure is between $800 \mathrm{kPa}$ and $1600 \mathrm{kPa}$, the increased cement content will decrease Es of the sample.

As can be seen from Figure 8, the change trend of Es of a single sample is divided into two types. When the cement content is less than $18 \%$, it shows a concave trend; when the content is greater than or equal to $18 \%$, it shows a convexconcave trend. When the cement content is less than $20 \%$, the minimum value of Es of the sample appears at a consolidation pressure of $400 \mathrm{kPa}$; when the content is $20 \%$, it appears at a pressure of $800 \mathrm{kPa}$. When the consolidation pressure is between $100 \mathrm{kPa}$ and $800 \mathrm{kPa}$, the increment of cement content can improve Es of the sample. Overall, the improvement effect on Es of the sample is the best with a cement content of $18 \%$. When the consolidation pressure is $1600 \mathrm{kPa}$, the increment of cement content will decrease Es of the sample.

The above test results show that when the structure of the particles produced in the cement hydration reaction is not damaged, the increasement of the particles can improve the compression modulus of the sample; when the structure is destroyed and recombined, the compression modulus of the particles after recombination is less than that of coastal soft soil particles. At this time, increasing the cement hydration reaction products will reduce the compression modulus of 
the sample. By comprehensive comparison, increasing the cement content by $18 \%$ has the best effect on the compression modulus of the sample.

\section{Test Results and Analysis of NCS}

4.1. Compression-Pressure Analysis. According to the test results and formula (1), the compression amount of nanomodified cement soil (NCS) samples after stabilization at various consolidation pressures was obtained, and the $d-p$ histograms of NCS-7 and NCS-28 were plotted, as shown in Figures 9 and 10.

It can be seen from Figure 9 that the change of the $d-p$ histogram of NCS-7 shows a "S" type. As the consolidation pressure increases, first the concave type increases and then the convex type. When the nanoclay content is $2 \%$, the compression amount of the sample increases. When the content is $4 \%$ and $8 \%$, the compression amount of the sample decreases. When the content is $6 \%$, there is a general modification effect on the compression. When the content is $10 \%$, the compression amount decreases when the consolidation pressure is between $200 \mathrm{kPa}$ and $400 \mathrm{kPa}$, and otherwise increases.

It can be seen from Figure 10 that the change of the $d-p$ histogram of NCS-28 also shows a "S" type. At the consolidation pressure less than or equal to $800 \mathrm{kPa}$, the addition of nanoclay can reduce the compression amount of the sample, but the nanoclay content has an effect on the reduction level. At the nanoclay content of $4 \%$ and $8 \%$, the reduction effect is better. At the consolidation pressure of $400 \mathrm{kPa}$ and the nanoclay content of $4 \%$, the reduction effect is the best, with a $29 \%$ decrease to $0.685 \mathrm{~mm}$. When the consolidation pressure is $1600 \mathrm{kPa}$, the compression amount decreases with a nanoclay content of $4 \%$ and $8 \%$, but otherwise increases.

The compression data of NCS samples in different curing ages are compared, as shown in Table 7.

It can be seen in Table 7 that an increase in the curing age will reduce the compression amount of NCS samples, and the reduction increases at the beginning and then decreases with the increase of consolidation pressure. The above test results show that the modification effect of nanoclay on the compression of CCS is closely related to the curing age. At a curing age of 7 days, the hydroscopicity of nanoclay will hinder the hydration reaction of cement, reducing the hydration reaction products of the cement and the early strength of the sample. The improvement effect is better with a nanoclay content of $4 \%$ and $8 \%$. At a curing age of 28 days, the filling and bonding effects of nanoclay play a major role, and the addition of nanoclay can better improve the compressibility of CCS. The degree of the pozzolanic reaction of nanoclay is better with a nanoclay content of $4 \%$, and the filling ability is better with a nanoclay content of $8 \%$.

In order to explore the improvement effect of nanoclay on the compression amount of CCS, the compression amounts of NCS and CCS at a curing age of 28 days and consolidation pressure between $100 \mathrm{kPa}$ and $400 \mathrm{kPa}$ are compared, as shown in Table 8.

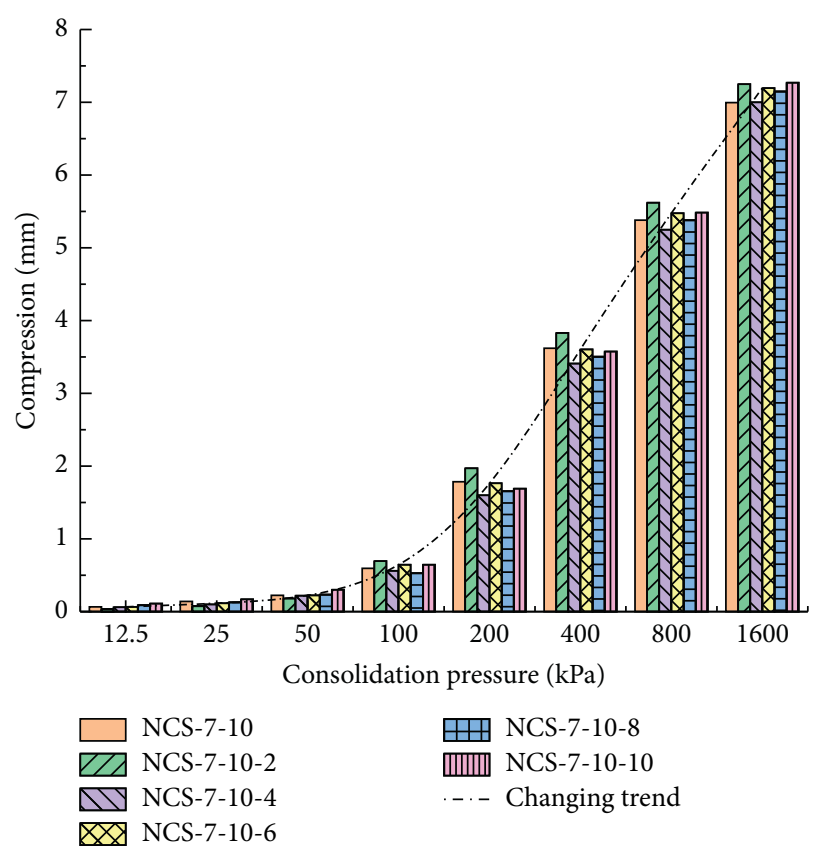

FIgURE 9: $d-p$ histogram of NCS-7 with different consolidation pressure.

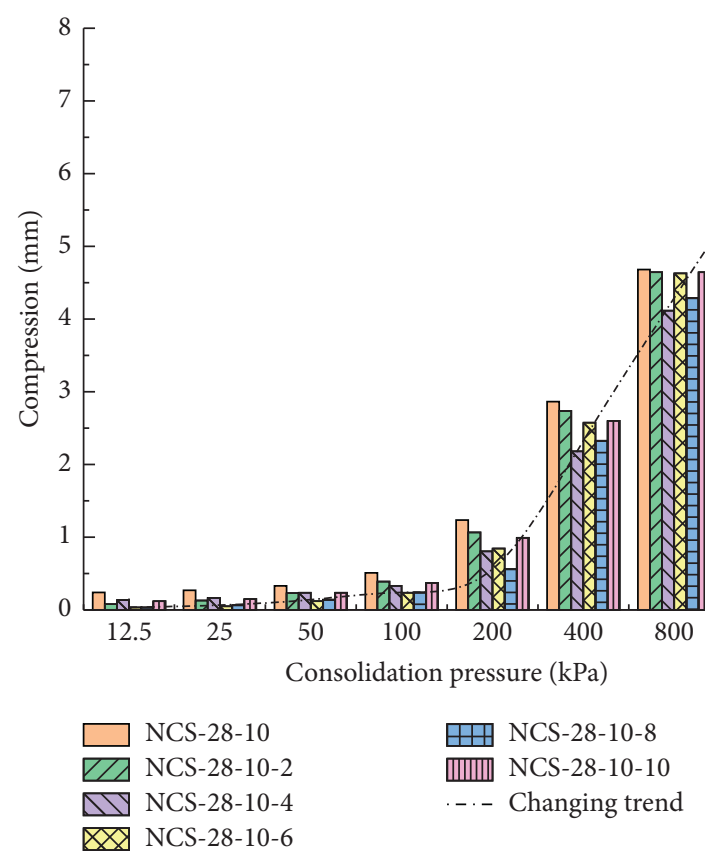

FIgURE 10: $d$ - $p$ histogram of NCS-28 with different consolidation pressure.

As shown in Table 8, at a consolidation pressure of $100 \mathrm{kPa}$, when the cement content is $18 \%$, the increment of cement content has the best effect on improving the compression of CCS samples, and a $2 \%$ increment will decrease the compression amount by $0.255 \mathrm{~mm}$. When the nanoclay content is $6 \%$, the increment of nanoclay content has the best effect, and a $2 \%$ increment will decrease the compression amount by $0.275 \mathrm{~mm}$. At this time, the improvement effect 
TABLE 7: Compression of NCS at different consolidation pressures.

\begin{tabular}{|c|c|c|c|c|c|c|}
\hline \multirow{2}{*}{ Nanoclay content (\%) } & \multirow{2}{*}{ Curing age $(d)$} & \multicolumn{5}{|c|}{ Compression deformation (mm) } \\
\hline & & $100 \mathrm{kPa}$ & $200 \mathrm{kPa}$ & $400 \mathrm{kPa}$ & $800 \mathrm{kPa}$ & $1600 \mathrm{kPa}$ \\
\hline \multirow{2}{*}{0} & 7 & 0.595 & 1.785 & 3.620 & 5.380 & 6.995 \\
\hline & 28 & 0.510 & 1.235 & 2.865 & 4.680 & 6.445 \\
\hline \multirow{2}{*}{2} & 7 & 0.695 & 1.970 & 3.830 & 5.620 & 7.250 \\
\hline & 28 & 0.390 & 1.065 & 2.735 & 4.645 & 6.510 \\
\hline \multirow{2}{*}{4} & 7 & 0.560 & 1.600 & 3.410 & 5.250 & 7.000 \\
\hline & 28 & 0.330 & 0.805 & 2.180 & 4.115 & 6.105 \\
\hline \multirow[b]{2}{*}{6} & 7 & 0.645 & 1.765 & 3.605 & 5.475 & 7.195 \\
\hline & 28 & 0.235 & 0.845 & 2.575 & 4.630 & 6.570 \\
\hline \multirow{2}{*}{8} & 7 & 0.530 & 1.655 & 3.505 & 5.380 & 7.150 \\
\hline & 28 & 0.240 & 0.560 & 2.325 & 4.290 & 6.190 \\
\hline \multirow{2}{*}{10} & 7 & 0.645 & 1.690 & 3.575 & 5.485 & 7.270 \\
\hline & 28 & 0.370 & 0.990 & 2.600 & 4.645 & 6.590 \\
\hline
\end{tabular}

TABLE 8: Comparison of compression between NCS and CCS.

\begin{tabular}{|c|c|c|c|c|c|c|}
\hline \multirow{2}{*}{ Sample code } & \multicolumn{6}{|c|}{ Compression and difference $(\mathrm{mm})$} \\
\hline & $100 \mathrm{kPa}$ & $d-d_{\mathrm{ccs}-28-10}$ & $200 \mathrm{kPa}$ & $d-d_{\mathrm{ccs}-28-10}$ & $400 \mathrm{kPa}$ & $d-d_{\text {ccs- } 28-10}$ \\
\hline CCS-28-10 & 0.510 & & 1.235 & & 2.865 & \\
\hline CCS-28-12 & 0.315 & 0.195 & 0.805 & 0.430 & 2.240 & 0.625 \\
\hline CCS-28-14 & 0.320 & 0.190 & 0.680 & 0.555 & 1.870 & 0.995 \\
\hline CCS-28-16 & 0.265 & 0.245 & 0.500 & 0.735 & 1.580 & 1.285 \\
\hline CCS-28-18 & 0.255 & 0.255 & 0.410 & 0.825 & 1.210 & 1.655 \\
\hline CCS-28-20 & 0.270 & 0.240 & 0.405 & 0.830 & 1.085 & 1.780 \\
\hline NCS-28-10 & 0.510 & & 1.235 & & 2.865 & \\
\hline NCS-28-10-2 & 0.390 & 0.120 & 1.065 & 0.170 & 2.735 & 0.130 \\
\hline NCS-28-10-4 & 0.330 & 0.180 & 0.805 & 0.430 & 2.180 & 0.685 \\
\hline NCS-28-10-6 & 0.235 & 0.275 & 0.845 & 0.390 & 2.575 & 0.290 \\
\hline NCS-28-10-8 & 0.240 & 0.270 & 0.560 & 0.675 & 2.325 & 0.540 \\
\hline NCS-28-10-10 & 0.370 & 0.140 & 0.990 & 0.245 & 2.600 & 0.265 \\
\hline
\end{tabular}

of $6 \%$ nanoclay content is 1.08 times that of $10 \%$ cement content on the compression of the sample. At a consolidation pressure of $200 \mathrm{kPa}$, when the cement content is $20 \%$, the increment of cement content has the best effect, and a $2 \%$ increment will decrease the compression amount by $0.830 \mathrm{~mm}$. When the nanoclay content is $8 \%$, the increment of nanoclay content has the best effect, and a $2 \%$ increment will decrease the compression amount by $0.675 \mathrm{~mm}$. At this time, the improvement effect of $8 \%$ nanoclay content is about equal to that of $5 \%$ cement content on the compression of the sample. At a consolidation pressure of $400 \mathrm{kPa}$, when the cement content is $20 \%$, the increment of cement content has the best effect, and a $2 \%$ increment will decrease the compression amount by $1.780 \mathrm{~mm}$. When the nanoclay content is $4 \%$, the increment of nanoclay content has the best effect, and a $2 \%$ increment will decrease the compression amount by $0.685 \mathrm{~mm}$. At this time, the improvement effect of $4 \%$ nanoclay content is equivalent to that of $2 \%$ cement content on the compression of the sample. The above research results show that the improvement effect of nanoclay at low consolidation pressure between $100 \mathrm{kPa}$ and $200 \mathrm{kPa}$ is better than that of the equivalent cement, but at high consolidation pressure between $400 \mathrm{kPa}$ and $1600 \mathrm{kPa}$, nanoclay is less effective at improving the compression than the equivalent amount of cement.
4.2. Analysis of Void Ratio Change. Based on the consolidation test results and formulas (1)-(3), the void ratios of NCS-7 and NCS-28 and their changes are obtained, as shown in Figure 11.

Figure 11 indicates that, as nanoclay content increases, the initial void ratio of the sample first increases and then decreases. With the same nanoclay content of less than $8 \%$, the initial void ratio increases with the growth of the curing age; when the nanoclay content is greater than or equal to $8 \%$, the initial void ratio decreases with the growth of the curing age. The change in the void ratio decreases with the growth of the curing age and decreases the most with a nanoclay content of $8 \%$, with a value of 0.14 . The final void ratio increases with the growth of the curing age and increases the most with a nanoclay content of $4 \%$, which is 0.17 . The above test results show that, at a curing age of 7 days, when the nanoclay content is less than $6 \%$, the addition of nanoclay will increase the initial void ratio; when the content is greater than or equal to $6 \%$, it will reduce the initial void ratio, and the filling effect is the best with a content of $8 \%$. At a curing age of 28 days, when the nanoclay content is less than $6 \%$, the improvement effect of nanoclay increment on the initial void ratio is weakened; when the content is greater than or equal to $6 \%$, the reduction effect of nanoclay increment on the initial void ratio is enhanced. 

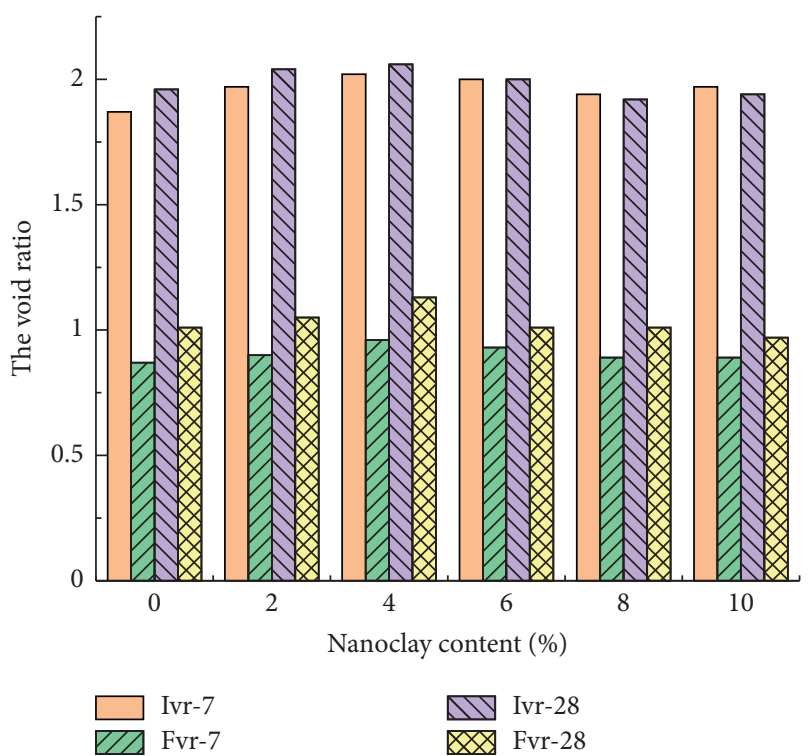

FIgUre 11: Change in the void ratio of NCS.

In order to investigate the reasons for the different effects of nanoclay content on compression of the samples, SEM tests were performed on 6 groups of NCS samples with different nanoclay content at a curing age of 28 days. The SEM method focuses the electron beam and turns it into an electron probe. Then, the electron probe is scanned by pointing it at the surface of the sample to detect the distribution of particles and pores on the sample, which is then converted into an image $[28,29]$. The results of this test method are clear and intuitive. Therefore, it is used to explore the mechanism for the improvement effect of different nanoclay contents on the sample, and the results are shown in Figure 12.

According to the quantitative analysis of microscopic images [30], it is found that small particles in the sample, as shown in Figure 12, increase with increased nanoclay content, and the bonding state between particles shows a state of alternating weakening and strengthening. Specifically, it is weakened in NCS-28-10-2 and NCS-28-10-6 and strengthened in other samples. With the increased nanoclay content, more small particles adhere to the larger particles, and the pore size first increases and then decreases. It increases in NCS-28-10-2 and gradually decreases in other groups of samples.

The above experimental results show that the bonding state of the sample is the best with a nanoclay content of $4 \%$; the filling effect is good with a content of $8 \%$ and $10 \%$; both the bonding state and filling effect of the sample are poor with a nanoclay content of $2 \%$.

4.3. Compression Modulus-Pressure Analysis. The values of $a_{1-2}$ for NCS-7 and NCS-28 are deduced according to formula (5), as shown in Figures 13 and 14.

As shown in Figure 13, with the increased nanoclay content, the value of $a_{1-2}$ of the sample first increases, then decreases, then increases, and finally decreases. The coefficient of compressibility increases with a nanoclay content of $2 \%$, but decreases with other contents. The value of $a_{1-2}$ of the sample is smaller with a nanoclay content of $4 \%$ and $10 \%$, as $1.571 \mathrm{MPa}^{-1}$ and $1.554 \mathrm{MPa}^{-1}$, respectively. It is shown that the compressibility of the sample can be well improved with a nanoclay content of $4 \%$ and $10 \%$.

As shown in Figure 14, with the increased nanoclay content, the coefficient of compressibility of the sample first decreases, then increases, then decreases, and finally increases. The minimum value is $0.467 \mathrm{MPa}^{-1}$ with a nanoclay content of $8 \%$. At this time, NCS changes from high- to medium-compressibility soil. Second, the coefficient of compressibility is smaller with a nanoclay content of $4 \%$, which is $0.727 \mathrm{MPa}^{-1}$. It is shown that the compressibility of the sample can be well improved with a nanoclay content of $8 \%$ and $4 \%$. This may be due to the combined effects of the physical filling and chemical bonding effects of nanoclay, which causes its compression amount to fluctuate up and down when the content of nanoclay is different.

Es values for NCS-7 and NCS-28 are obtained according to formula (4), and Es-p diagrams are plotted, as shown in Figures 15 and 16.

As can be seen from Figure 15, the change of Es of a single sample shows a concave trend. The minimum values of $E s$ are all at a consolidation pressure of $200 \mathrm{kPa}$. When the consolidation pressure is between $100 \mathrm{kPa}$ and $200 \mathrm{kPa}$, Es of the sample increases with a nanoclay content of $4 \%, 8 \%$, and $10 \%$, but decreases with a content of $2 \%$. When the pressure is between $400 \mathrm{kPa}$ and $1600 \mathrm{kPa}$, the addition of nanoclay mainly reduces $E s$ of the sample.

As can be seen from Figure 16, the changing trend of $E s$ of a single sample shows a concave type. The minimum values of $E s$ are all at the consolidation pressure of $400 \mathrm{kPa}$. The main reason for this phenomenon is that the sample reaches the limit when the consolidation pressure is $400 \mathrm{kPa}$, and the internal particles are destroyed, resulting in larger pores; as the consolidation pressure continues to increase, the damaged particles are forced to squeeze each other so that the pores become smaller. When the consolidation pressure is less than $800 \mathrm{kPa}$, the addition of nanoclay can improve $E s$, and when the nanoclay content is $4 \%$ and $8 \%$, the improvement effect is the best; when the consolidation pressure is greater than or equal to $800 \mathrm{kPa}$, the addition of nanoclay can decrease $E s$ of the sample. The above test results show that the improvement effect of nanoclay content on Es of the sample is related to consolidation pressure. When the consolidation pressure is greater than or equal to $800 \mathrm{kPa}$, the addition of nanoclay will reduce Es of the sample; when the pressure is less than $800 \mathrm{kPa}$ and the sample is at a different curing age, the improvement effect of nanoclay on $E s$ is different. By comprehensive comparison, when the consolidation pressure is between $12.5 \mathrm{kPa}$ and $800 \mathrm{kPa}$ with a nanoclay content of $4 \%$, the comprehensive improvement effect on the consolidation characteristics is better.

\section{Compression Amount Prediction}

5.1. Compression Amount Prediction of CCS. Compression prediction is based on a combination of the constitutive 


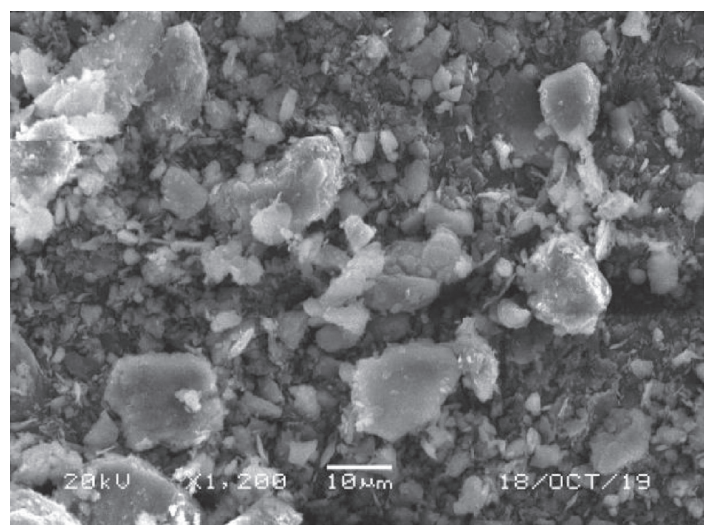

(a)

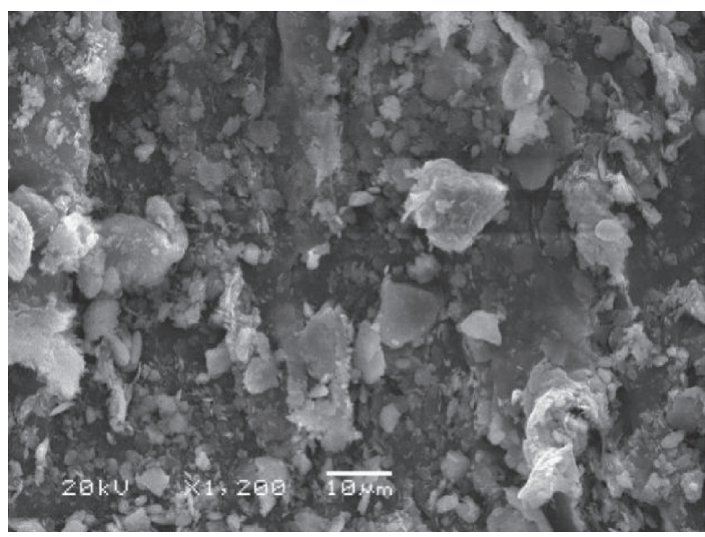

(c)

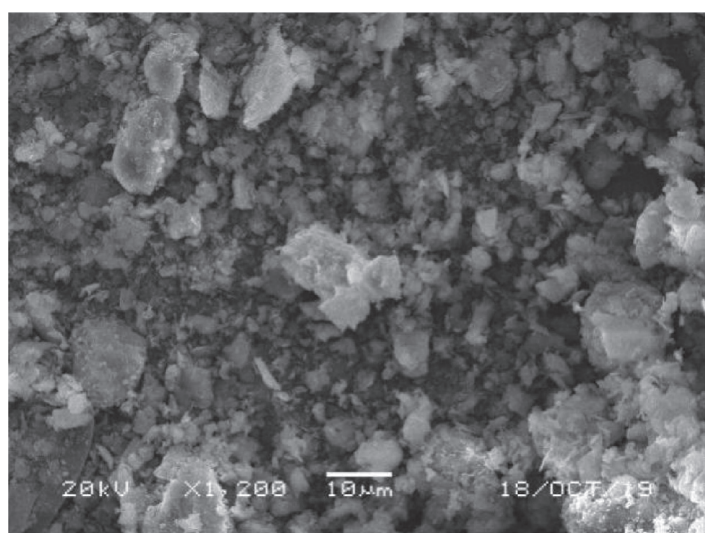

(e)

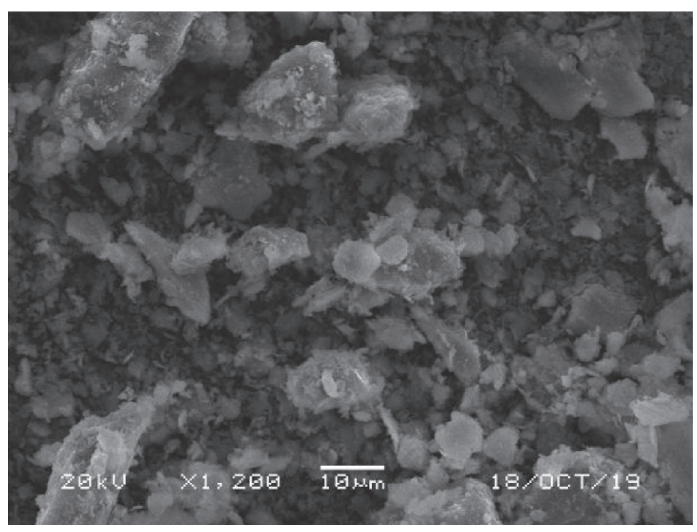

(b)

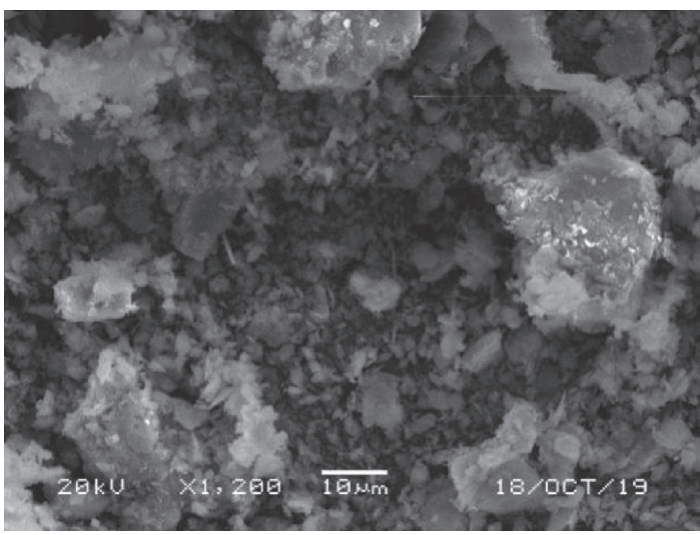

(d)

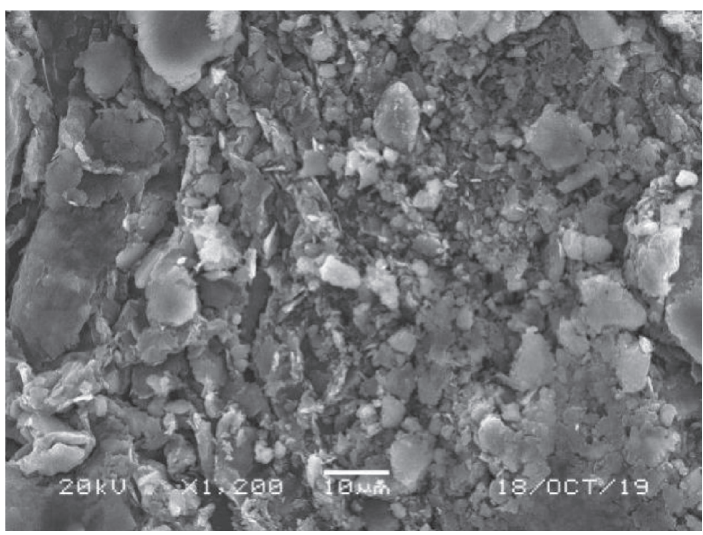

(f)

FiguRe 12: Microstructure of nano-modified cement soil: (a) NCS-28-10; (b) NCS-28-10-2; (c) NCS-28-10-4; (d) NCS-28-10-6; (e) NCS-2810-8; (f) NCS-28-10-10.

model, consolidation theory, and finite element method for theoretical prediction, or according to the observed trend of the settlement value, to find a mathematical model that fits the trend and performs the reasonable prediction [31, 32]. With the first method, we need to know the stress-strain relationship, boundary conditions, and coefficient of permeability of the sample to derive a mathematical model [33]. These data are relatively easy to measure in the laboratory, but measured data are quite different from actual engineering situations which need further study before it can be popularized and applied. The second method is a prediction based on field data: the settlement data observed in the field are sorted out, the changing trend is analyzed, and the function that can express the changing trend is found and fitted to complete the settlement prediction [34]. This method is simple to operate and has high practicability. Many studies have been conducted based on this method and expanded it from a simple hyperbolic and exponential model [35] to a logical, dynamic, and combinatorial model [36]. Since the $d$-p curves of the CCS and NCS samples in this study are both in the shape of "S," the traditional hyperbolic and exponential models are not well-fitting. 


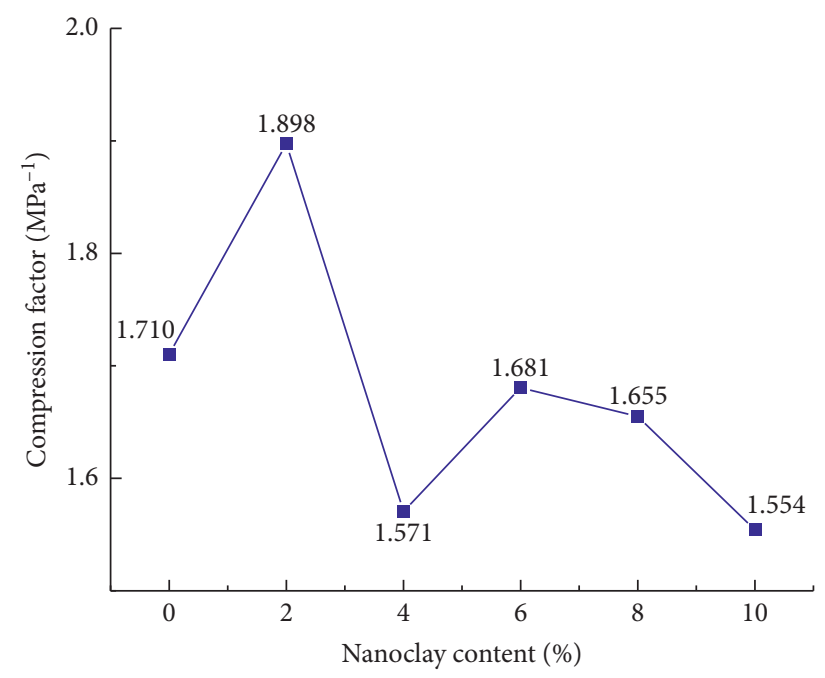

Figure 13: $a_{1-2}$ of NCS-7 of different nanoclay content.

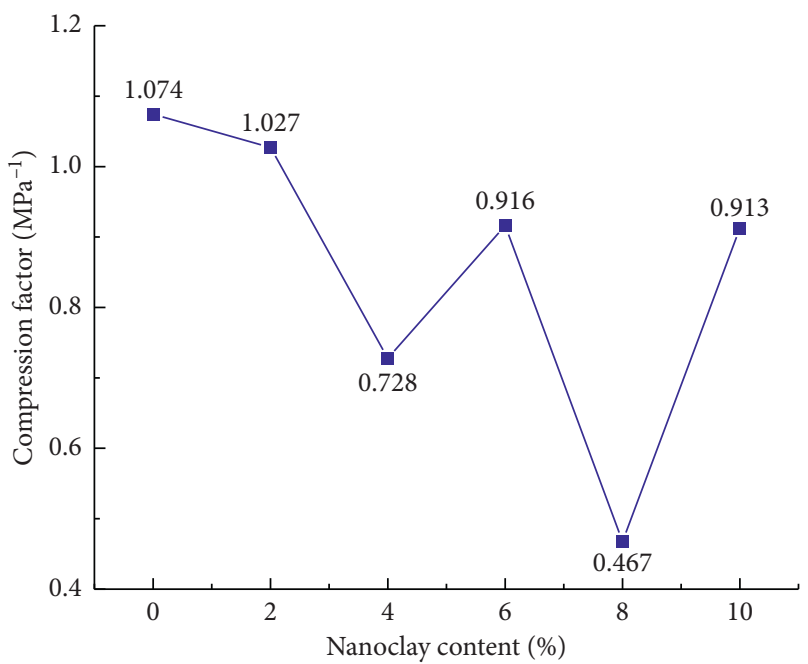

Figure 14: $a_{1-2}$ of NCS-28 of different nanoclay content.

Consider establishing a new model to better fit the $d$ - $p$ curve in this experiment.

The second method is used to predict the compression amount. The specific steps are as follows:

(1) Determine the trend line characteristics: the compression pressure curves of CCS and NCS samples were analyzed. It was found that they have the same trends and characteristics; both are "S" type curves. CCS-28-12 was taken as an example, as shown in Figure 17.

As can be seen from Figure 17, the compression amount of the sample is 0 at a consolidation pressure of $0 \mathrm{kPa}$. The pressure starts from $12.5 \mathrm{kPa}$, the slope of the curve is greater than 0 , and the compression amount increases progressively. Therefore, the minimum value of the compression amount is at $12.5 \mathrm{kPa}$, and the maximum is $1600 \mathrm{kPa}$. Because soil particles are incompressible, the volume change of the sample is entirely caused by the pore change, and the compression amount has an upper bound. The curve is concave and convex at first with an "S" type, that is, it slowly increases to a certain value, then increases rapidly, then slowly increases, and then gradually flattens.

(2) Select the function model: the cosine function has an upper bound of 1 and a lower bound of 0 , goes through the origin, and increases monotonically between 0 and 1 . The composite compression pressure data in the upper and lower bounds and the first derivative are shown in the following formula:

$$
y=\cos x
$$

In order to enable the cosine function to simulate the change of the measured data, the first coefficient $s_{w}$ was increased to improve the upper bound of the function. 


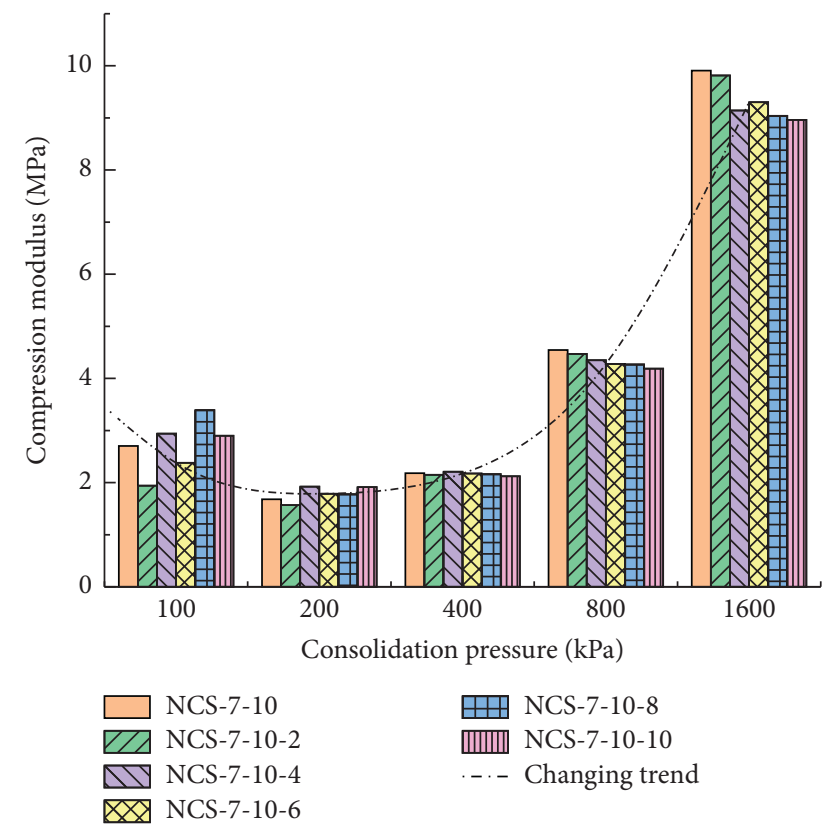

Figure 15: Es of NCS-7 with different consolidation pressure.

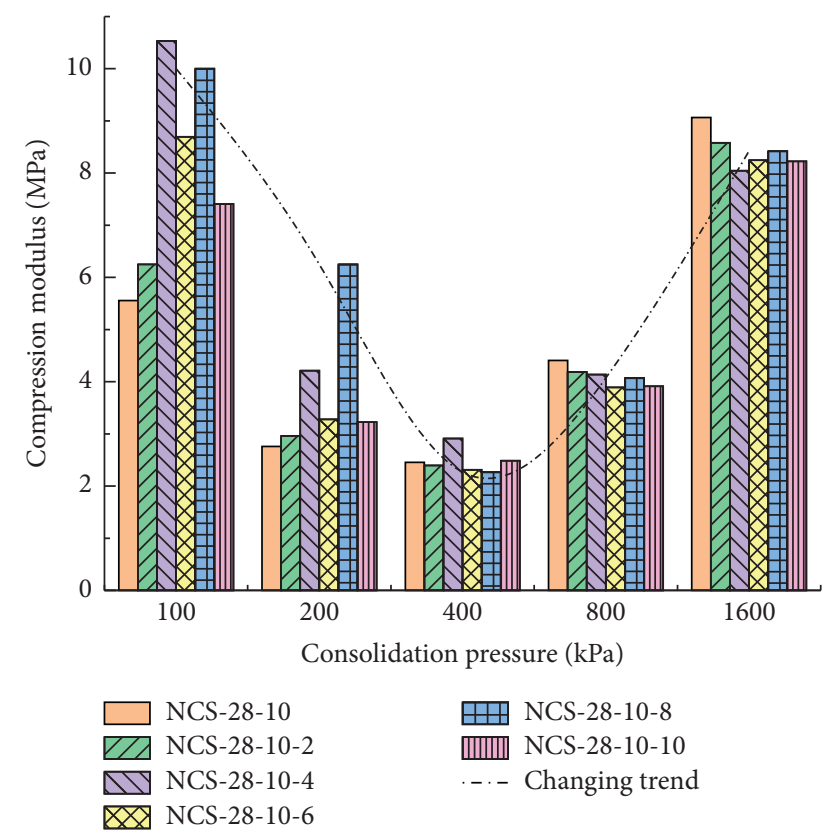

FIgURE 16: Es of NCS-28 with different consolidation pressure.

The power and exponential functions were increased to make the second derivative of the cosine function change to meet the change requirements of the " $\mathrm{S}$ " type, to form the cosine-power function-exponential model, as shown in the following formula:

$$
s=s_{w} \cos \frac{k e^{-b x}}{2}
$$

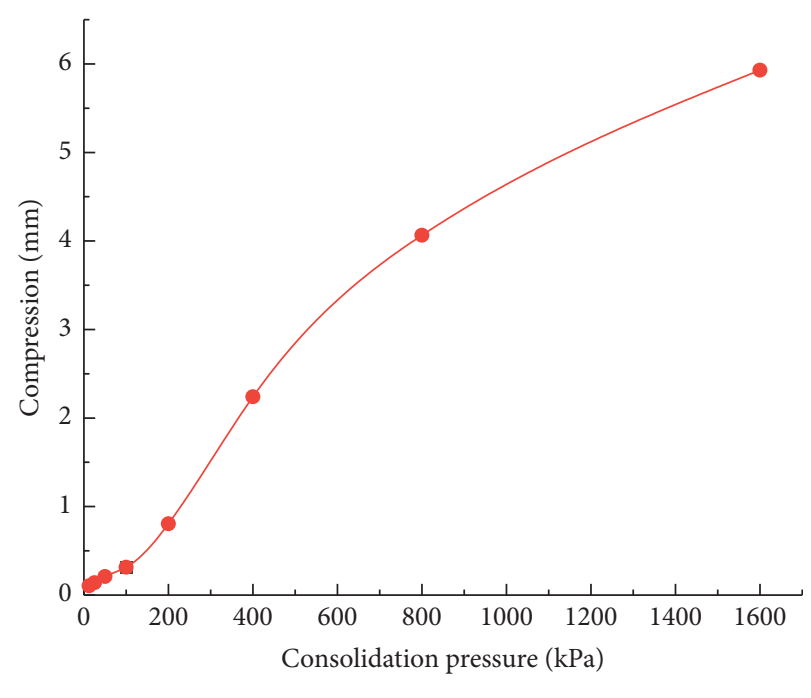

CCS-28-12

Figure 17: $d-p$ curve of CCS-28-12.

where $s$ represents the required amount of compression, $s_{w}$ represents the upper bound, and $k$ and $b$ are constants.

(3) Conduct function fitting: function fitting was performed in Origin software, and the results are shown in Figure 18.

As shown in Figure 18, the fitted curves pass the measured data points with better fitting effect. Therefore, they can be used to predict the compression of the sample and solve the parameters in the model.

(4) Solve the parameters: Origin software was used to fit the model to convergence, and the values of $s_{w}, k$, and $b$ with different cement content were obtained, as shown in Table 9.

The fitting accuracy $R^{2}$ of different cement content in Table 9 can reach 0.99 , with better fitting result. Therefore, formula (7) can be used to fit the measured value of the compression pressure of CCS samples. After substituting the data of $s_{w}$ in Table 10 into formula (7), the compression pressure prediction models of CCS samples with a cement content of $10 \%, 12 \%, 14 \%, 16 \%, 18 \%$, and $20 \%$ can be obtain obtained, respectively.

Because the water content of the sample in this test was $80 \%$, the cement content was between $10 \%$ and $20 \%$, and the consolidation pressure was between $12.5 \mathrm{kPa}$ and $1600 \mathrm{kPa}$; formula (8) only had high accuracy for CCS samples that met these conditions.

(5) Verify fitting results: since the compression amount of the sample at a consolidation pressure between $12.5 \mathrm{kPa}$ and $50 \mathrm{kPa}$ was greatly affected by the preparation method, the test results were prone to deviation. Therefore, in the process of verifying 


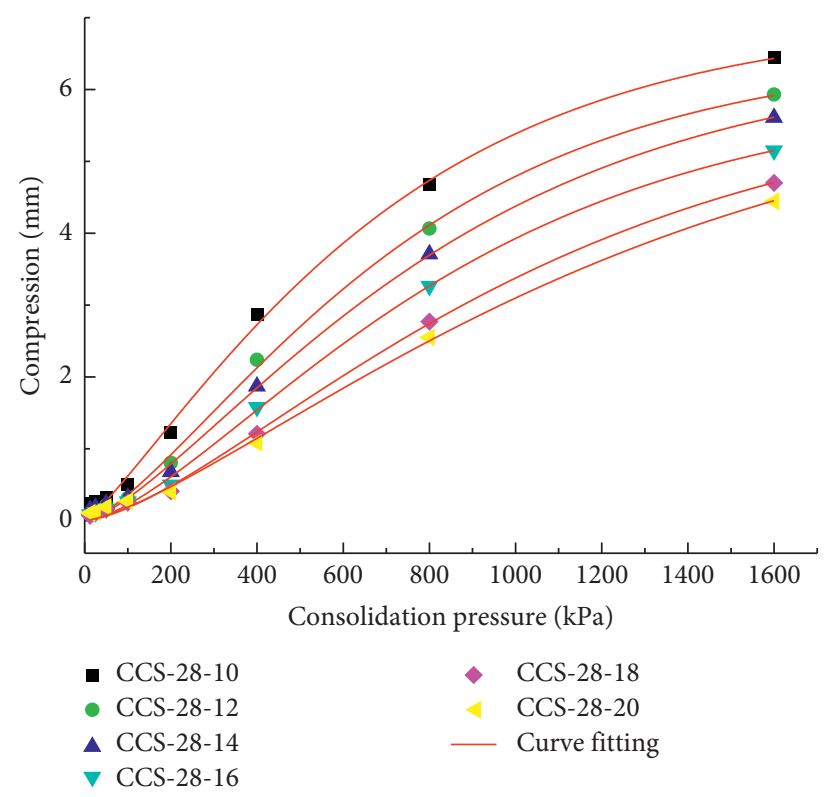

FIGURE 18: Fitting results with different consolidation pressure.

TABLE 9: $s_{w}, k$, and $b$ values with different cement content.

\begin{tabular}{lcccccc}
\hline Cement content & $10 \%$ & $12 \%$ & $14 \%$ & $16 \%$ & $18 \%$ & $20 \%$ \\
\hline$s_{w}$ & 6.997 & 6.533 & 6.463 & 6.002 & 6.000 & 6.228 \\
$k$ & 1.216 & 1.457 & 1.436 & 1.560 & 1.528 & 1.406 \\
$b$ & 0.000908 & 0.000914 & 0.000802 & 0.000801 & 0.000657 & 0.000538 \\
\hline
\end{tabular}

TABLE 10: $s_{w}, k$, and $b$ values with different nanoclay content.

\begin{tabular}{lccc}
\hline Nanoclay content $(\%)$ & $s_{w}$ & $k$ & $b$ \\
\hline 4 & 6.105 & 1.74375 & 0.00116 \\
\hline
\end{tabular}

fitting results, the compression amount at a consolidation pressure between $100 \mathrm{kPa}$ and $1600 \mathrm{kPa}$ is mainly verified.

The $x$ values of $100,200,400,800$, and 1600 were substituted into formula (7), respectively, and the predicted values of compression of the sample with different cement content were obtained.

Consolidation tests were performed on six groups of CCS samples at a curing age of 28 days and cement content of $10 \%, 12 \%, 14 \%, 16 \%, 18 \%$, and $20 \%$. The compression value corresponding to the consolidation pressure at each level was taken as the measured value, as shown in Table 11.

As shown in Table 11, the standard deviations are mostly less than 0.05 , indicating that the predicted values are closer to the measured values with better fitting results.

\subsection{Compression Prediction of NCS}

5.2.1. Function Fitting. The study found that the $d-p$ curves of NCS and CCS samples have the same trend and characteristics, both of which are "S"-shaped curves, and when the nanoclay content is $4 \%$, the compression modification effect on CCS is better. Therefore, a compression prediction model was established for NCS samples with a nanoclay content of $4 \%$. Formula (7) was used to fit the function in Origin software. The fitting results are shown in Figure 19.

As can be seen in Figure 19, the fitting results slightly deviate at consolidation pressure of $400 \mathrm{kPa}$ and $800 \mathrm{kPa}$, but better-fitting at other consolidation pressure values. Therefore, it was determined to use this model to predict the compression of the sample and solve the parameters in the model.

5.2.2. Parameter Solving. Origin software was used to solve $s_{w}, k$, and $b$, and the values are shown in Table 10 .

According to the model parameters in Table 10, the fitting accuracy $R^{2}$ is 0.99 when the content of nanoclay is $4 \%$, with good fitting effect. Therefore, the data in Table 10 were substituted into formula (7) to calculate the prediction model of the compression amount of NCS samples at a curing age of 28 days with a nanoclay content of $4 \%$, as shown in the following formula: 
TABLE 11: Calculated value corresponding to different consolidation pressure under different cement content.

\begin{tabular}{|c|c|c|c|c|c|c|}
\hline Cement content $(\%)$ & Numeric type & $100 \mathrm{kPa}$ & $200 \mathrm{kPa}$ & $400 \mathrm{kPa}$ & $800 \mathrm{kPa}$ & $1600 \mathrm{kPa}$ \\
\hline \multirow{3}{*}{10} & Measured value & 0.640 & 1.310 & 2.940 & 4.770 & 6.470 \\
\hline & Predictive value & 0.622 & 1.351 & 2.728 & 4.735 & 6.434 \\
\hline & Standard deviation & 0.0091 & 0.0203 & 0.1061 & 0.0174 & 0.0180 \\
\hline \multirow{3}{*}{12} & Measured value & 0.330 & 0.840 & 2.210 & 4.040 & 5.980 \\
\hline & Predictive value & 0.363 & 0.918 & 2.128 & 4.112 & 5.920 \\
\hline & Standard deviation & 0.0163 & 0.0389 & 0.0408 & 0.0360 & 0.0301 \\
\hline \multirow{3}{*}{14} & Measured value & 0.290 & 0.740 & 1.980 & 3.810 & 5.630 \\
\hline & Predictive value & 0.313 & 0.790 & 1.849 & 3.695 & 5.616 \\
\hline & Standard deviation & 0.0117 & 0.0250 & 0.0653 & 0.0577 & 0.0071 \\
\hline \multirow{3}{*}{16} & Measured value & 0.250 & 0.570 & 1.550 & 3.260 & 5.170 \\
\hline & Predictive value & 0.224 & 0.611 & 1.540 & 3.267 & 5.151 \\
\hline & Standard deviation & 0.0131 & 0.0207 & 0.0048 & 0.0036 & 0.0095 \\
\hline \multirow{3}{*}{18} & Measured value & 0.200 & 0.490 & 1.160 & 2.770 & 4.710 \\
\hline & Predictive value & 0.179 & 0.485 & 1.236 & 2.743 & 4.706 \\
\hline & Standard deviation & 0.0105 & 0.0025 & 0.0378 & 0.0136 & 0.0019 \\
\hline \multirow{3}{*}{20} & Measured value & 0.200 & 0.460 & 1.140 & 2.610 & 4.480 \\
\hline & Predictive value & 0.188 & 0.475 & 1.147 & 2.503 & 4.454 \\
\hline & Standard deviation & 0.0059 & 0.0075 & 0.0037 & 0.0537 & 0.0129 \\
\hline
\end{tabular}

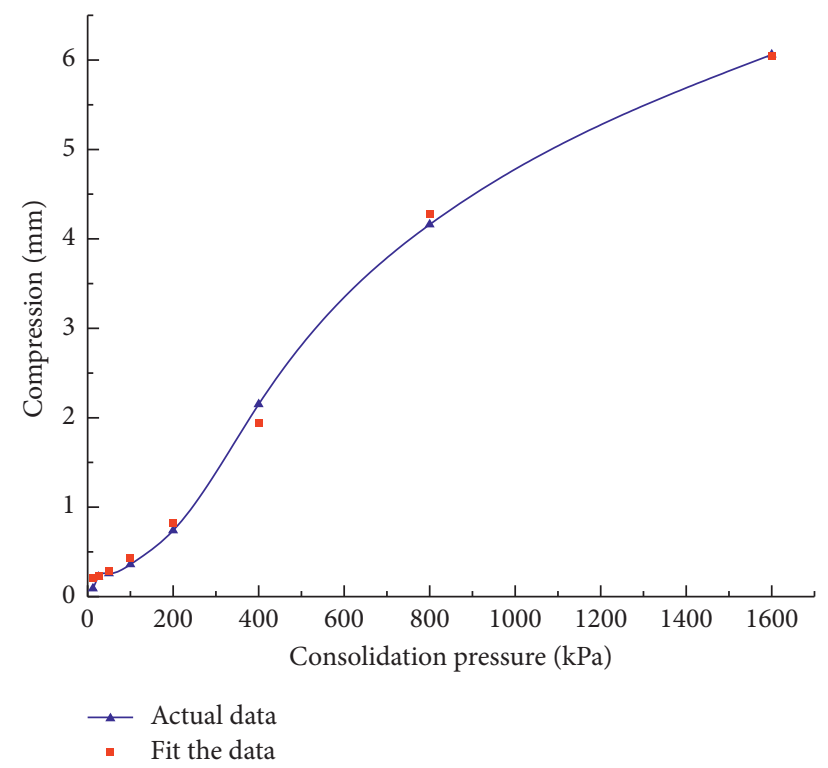

FIGURE 19: Fitting results with different consolidation pressure.

TABLE 12: Value of different consolidation pressure.

\begin{tabular}{lccccc}
\hline Numeric type & $100 \mathrm{kPa}$ & $200 \mathrm{kPa}$ & $400 \mathrm{kPa}$ & $800 \mathrm{kPa}$ & 4.13 \\
Measured value & 0.25 & 0.77 & 2.19 & 4.26 & 5.94 \\
Predictive value & 0.28 & 0.84 & 2.16 & 0.02 & 0.06 \\
Standard deviation & 0.02 & 0.03 & 0.02 & 0.08 \\
\hline
\end{tabular}

$$
s=6.105 \cos ^{1.74375} \frac{\pi e^{-0.00116 x}}{2} .
$$

5.2.3. Verification of Fitting Results. The compression amount at a consolidation pressure between $100 \mathrm{kPa}$ and $1600 \mathrm{kPa}$ was verified. The $x$ values of $100 \mathrm{kPa}, 200,400,800$, and 1600 , were substituted into the formula. The predicted value of the compression amount of NCS samples at a curing age of 28 days with a nanoclay content of $4 \%$ was obtained.

Consolidation tests were performed on NCS samples at a curing age of 28 days with a nanoclay content of $4 \%$. The compression pressure data were obtained. The compression amount corresponding to the consolidation pressure at each level was measured. The predicted value of compression was compared with the measured value, as shown in Table 12. 
As shown in Table 12, the standard deviation is smaller with a maximum value of 0.08 , indicating that the prediction result of formula (8) is better.

\section{Conclusions and Discussions}

\subsection{Conclusions}

(1) There is a linear interval in the improvement effect of the increment of cement content on the compression of CCS. In this test, cement content in this interval is between $12 \%$ and $18 \%$. The improvement effect on the compression amount, compressibility, and compression modulus of CCS is better with a cement content of $18 \%$.

(2) The improvement effect of nanoclay content on the compressibility of the sample is greatly affected by the curing age. When the nanoclay content is $4 \%$ and $8 \%$, the improvement effect is better; when the nanoclay content is $2 \%$, the improvement effect is poor. When the consolidation pressure is between $100 \mathrm{kPa}$ and $800 \mathrm{kPa}$, NCS with a nanoclay content of $4 \%$ is preferred.

(3) Microscopic test results show that adhesion is better with a nanoclay content of $4 \%$, and the filling effect is better with a nanoclay content of $8 \%$.

(4) A cosine-power function-exponential model is proposed to fit the measured data, and the fitting effect is better. And, establish a model to predict the compression of CCS and NCS.

6.2. Discussions. It should be noted that the samples studied in this study are still limited, and the following topics deserve further in-depth study:

(1) Based on a cement content of $18 \%$, it is necessary to explore the effect of different nanoclay contents on the compressibility of NCS

(2) With nanoclay contents of $4 \%$ and $8 \%$, the influences of different cement contents on the consolidation characteristics and improvement effect of NCS could be studied

(3) It is of great importance to optimize the compression prediction model of coastal cement soil and to investigate the model parameters of other cement soil

\section{Data Availability}

The data used to support the findings of this study are available from the corresponding author upon request.

\section{Conflicts of Interest}

The authors declare that they have no conflicts of interest.

\section{Authors' Contributions}

W.Y. and M.D. analyzed the study; N.L. and P.J. wrote and edited the review; D.A. investigated the study; B.Q. and W.W. conceptualized the study.

\section{Acknowledgments}

This research was funded by the National Natural Science Foundation of China (Grant no. 41772311), Zhejiang Provincial Natural Science Foundation of China (Grant no. Q20E080042), Open Research Fund of State Key Laboratory of Geomechanics and Geotechnical Engineering, Institute of Rock and Soil Mechanics, Chinese Academy of Science (Grant no. Z017013), and Scientific Research Projects of Zhejiang Department of Housing and Urban and Rural Construction of China (Grant nos. 2017K179 and 2019K171).

\section{References}

[1] Y. Liu, F.-H. Lee, S.-T. Quek, E. J. Chen, and J.-T. Yi, "Effect of spatial variation of strength and modulus on the lateral compression response of cement-admixed clay slab," Géotechnique, vol. 65, no. 10, pp. 851-865, 2015.

[2] N. Li, Y. Zhu, F. Zhang, S. M. Lim, W. Wu, and W. Wang, "Unconfined compressive properties of fiber-stabilized coastal cement clay subjected to freeze-thaw cycles," Journal of Marine Science and Engineering, vol. 9, no. 2, p. 143, 2021.

[3] M. Chen, S.-L. Shen, A. Arulrajah, H.-N. Wu, D.-W. Hou, and Y.-S. $\mathrm{Xu}$, "Laboratory evaluation on the effectiveness of polypropylene fibers on the strength of fiber-reinforced and cement-stabilized Shanghai soft clay," Geotextiles and Geomembranes, vol. 43, no. 6, pp. 515-523, 2015.

[4] Y. Pan, M. A. Hicks, and W. Broere, "An efficient transientstate algorithm for evaluation of leakage through defective cutoff walls," International Journal for Numerical and Analytical Methods in Geomechanics, vol. 45, no. 1, pp. 108-131, 2021.

[5] W. Wang, J. Li, and J. Jun $\mathrm{Hu}$, "Unconfined mechanical properties of nanoclay cement compound modified calcareous sand of the South China Sea," Advances in Civil Engineering, vol. 2020, Article ID 6623710, 16 pages, 2020.

[6] Y. Liu, L. Q. He, Y. J. Jiang, M. M. Sun, E. J. Chen, and F.-H. Lee, "Effect of in situ water content variation on the spatial variation of strength of deep cement-mixed clay," Géotechnique, vol. 69, no. 5, pp. 391-405, 2019.

[7] E. Mengue, H. Mroueh, L. Lancelot, and R. Medjo Eko, "Physicochemical and consolidation properties of compacted lateritic soil treated with cement," Soils and Foundations, vol. 57, no. 1, pp. 60-79, 2017.

[8] Y. Li, Y. Z. Tan, J. Jiang, and C. F. Xia, "Experimental study on the compressibility of cement improved laterite soil," Applied Mechanics and Materials, vol. 170-173, pp. 371-374, 2012.

[9] R. Khandelwal, J. Senthilnath, S. N. Omkar, and N. Shivanath, "A novel multiobjective optimization for cement stabilized soft soil based on artificial bee colony," International Journal of Applied Metaheuristic Computing, vol. 7, no. 4, pp. 1-17, 2016.

[10] D.-F. Lin and M.-C. Tsai, "The effects of nanomaterials on microstructures of sludge ash cement paste," Journal of the Air \& Waste Management Association, vol. 56, no. 8, pp. 11461154, 2012.

[11] H.-M. Kwon, A. T. Le, and N. T. Nguyen, "Influence of soil grading on properties of compressed cement-soil," KSCE Journal of Civil Engineering, vol. 14, no. 6, pp. 845-853, 2010.

[12] E. Mengue, H. Mroueh, L. Lancelot, and R. Medjo Eko, "Evaluation of the compressibility and compressive strength of a compacted cement treated laterite soil for road 
application," Geotechnical and Geological Engineering, vol. 36, no. 6, pp. 3831-3856, 2018.

[13] N. Li, Q. Zhu, W. Wang, F. Song, D. An, and H. Yan, "Compression characteristics and microscopic mechanism of coastal soil modified with cement and fly ash," Materials, vol. 12, no. 19, Article ID 3182, 2019.

[14] K. H. Lee and S. Lee, "Mechanical properties of weakly bonded cement stabilized kaolin," KSCE Journal of Civil Engineering, vol. 6, no. 4, pp. 389-398, 2002.

[15] S. Çelik, "An experimental investigation of utilizing waste red mud in soil grouting," KSCE Journal of Civil Engineering, vol. 21, no. 4, pp. 1191-1200, 2016.

[16] J. Mao, Q. Wu, F. Tao, W. Xu, T. Hong, and Y. Dong, "Facile fabrication of porous $\mathrm{BiVO}_{4}$ hollow spheres with improved visible-light photocatalytic properties," RSC Advances, vol. 10, no. 11, pp. 6395-6404, 2020.

[17] B. Funk, D. Göhler, B. Sachsenhauser et al., "Impact of freezethaw weathering on integrity, internal structure and particle release from micro- and nanostructured cement composites," Environmental Science: Nano, vol. 6, no. 5, pp. 1443-1456, 2019.

[18] W. Wang, C. Zhang, N. Li, F. Tao, and K. Yao, "Characterisation of nano magnesia-cement-reinforced seashore soft soil by direct-shear test," Marine Georesources \& Geotechnology, vol. 37, no. 8, pp. 989-998, 2019.

[19] K. Yao, D. An, W. Wang, N. Li, C. Zhang, and A. Zhou, "Effect of nano-MgO on mechanical performance of cement stabilized silty clay," Marine Georesources \& Geotechnology, vol. 38, no. 2, pp. 250-255, 2020.

[20] W. Wang, Y. Li, K. Yao, N. Li, A. Zhou, and C. Zhang, "Strength properties of nano-MgO and cement stabilized coastal silty clay subjected to sulfuric acid attack," Marine Georesources \& Geotechnology, vol. 38, no. 10, pp. 1177-1186, 2020.

[21] K. Yao, W. Wang, N. Li, C. Zhang, and L. Wang, "Investigation on strength and microstructure characteristics of Nano-MgO admixed with cemented soft soil," Construction and Building Materials, vol. 206, pp. 160-168, 2019.

[22] M. A. Langaroudi and M. Yaghoub, "Effect of nano-clay on the freeze-thaw resistance of self-compacting concrete containing mineral admixtures," European Journal of Environmental and Civil Engineering, pp. 1-20, 2019.

[23] S. A. Shakrani, A. Ayob, and M. A. Ab Rahim, "A review of nanoclay applications in the pervious concrete pavement," AIP Conference Proceedings, vol. 1885, no. 1, Article ID 020049, 2017.

[24] M. H. Niaki, A. Fereidoon, and M. G. Ahangari, "Experimental study on the mechanical and thermal properties of basalt fiber and nanoclay reinforced polymer concrete," Composite Structures, vol. 191, pp. 231-238, 2018.

[25] A. J. Choobbasti and S. S. Kutanaei, "Microstructure characteristics of cement-stabilized sandy soil using nanosilica," Journal of Rock Mechanics and Geotechnical Engineering, vol. 9, no. 5, pp. 981-988, 2017.

[26] S. Y. Zhang, Y. F. Fan, H. Y. Luan, and Y. Chan, "Effect of disperse condition of nano-clay on behavior of cement paste," Journal of Building Materials, vol. 16, no. 2, pp. 197-202, 2013.

[27] GB/T 50123-2019, Standard for Geotechnical Test Methods, China Planning Press, Beijing, China, 2019.

[28] K. M. Ewa, "Sem investigations of clay subjected to $200 \mathrm{MPa}$ pressure," Procedia Earth and Planetary Science, vol. 15, pp. 791-796, 2015.

[29] X. L. Wang, S. X. Yan, and H. Q. Wen, "Experimental analysis on microstructure and mineral composition of Jurassic soft rock in Shajihai mining area of Xinjiang," Applied Mechanics and Materials, vol. 353-356, pp. 24-27, 2013.

[30] L. Z. Zhang, R. L. Hu, X. Q. Li, and Y. B. Zhang, "Soil microstructure quantitative analysis system and its application," Geological Science and Technology Information, vol. 27, no. 1, pp. 108-112, 2008.

[31] X. H. Tu, Z. L. Wang, and Z. M. Liang, "Study on application of modified Weibull model to settlement prediction of foundation," Rock and Soil Mechanics, vol. 26, no. 4, pp. 621-628, 2005.

[32] Z. Fan, Y. Zhang, H. A. Wu, Y. Kang, and D. Jiang, "Subsidence monitoring and prediction of high-speed railway in Beijing with multitemporal TerraSAR-X data," in Proceedings of the MIPPR 2017: Multispectral Image Acquisition, Processing, and Analysis, Xiangyang, China, February 2018.

[33] H. D. Liu, L. D. Li, S. L. Zhao, and S. H. Hu, "Complete stress-strain constitutive model considering crack model of brittle rock," Environmental Earth Sciences, vol. 78, p. 629, 2019.

[34] Q. Yang, W.-m. Leng, S. Zhang et al., "Long-term settlement prediction of high-speed railway bridge pile foundation," Journal of Central South University, vol. 21, no. 6, pp. 24152424, 2014, in Chinese.

[35] G. W. Mang, "Application of exponential curve model in subgrade settlement prediction," Value Engineering, no. 50, pp. 81-83, 2014.

[36] T. P. Chang, J. Y. Shih, and K. M. Yang, "Neural network prediction of the high-fill road foundation settlement of highway," Journal of Engineering Geology, vol. 12, no. 4, pp. 427-431, 2004. 